Published in final edited form as:

Biomaterials. 2017 January ; 112: 95-107. doi:10.1016/j.biomaterials.2016.10.019.

\title{
Shifts in macrophage phenotype at the biomaterial interface via IL-4 eluting coatings are associated with improved implant integration
}

\author{
Daniel Hachim ${ }^{a, b}$, Samuel T. LoPresti ${ }^{a, b}$, Cecelia C. Yates ${ }^{a, c}$, and Bryan N. Brown ${ }^{a, b, d,{ }^{*}}$ \\ aMcGowan Institute for Regenerative Medicine, University of Pittsburgh. 450 Technology Drive, \\ Suite 300. Pittsburgh, PA 15219. \\ ${ }^{b}$ Department of Bioengineering, Swanson School of Engineering, University of Pittsburgh. 302 \\ Benedum Hall, 3700 O'Hara Street, Pittsburgh, PA 15260. \\ 'Department of Health Promotion and Development, School of Nursing, University of Pittsburgh. \\ 440 Victoria Building, 3500 Victoria Street, Pittsburgh, PA 15213. \\ dDepartment of Obstetrics, Gynecology and Reproductive Sciences, University of Pittsburgh. 300 \\ Halket Street, Pittsburgh, PA 15213.
}

\section{Abstract}

The present study tests the hypothesis that transient, early-stage shifts in macrophage polarization at the tissue-implant interface from a pro-inflammatory (M1) to an anti-inflammatory/regulatory (M2) phenotype mitigates the host inflammatory reaction against a non-degradable polypropylene mesh material and improves implant integration downstream. To address this hypothesis, a nanometer-thickness coating capable of releasing IL-4 (an M2 polarizing cytokine) from an implant surface at early stages of the host response has been developed. Results of XPS, ATRFTIR and Alcian blue staining confirmed the presence of a uniform, conformal coating consisting of chitosan and dermatan sulfate. Immunolabeling showed uniform loading of IL-4 throughout the surface of the implant. ELISA assays revealed that the amount and release time of IL-4 from coated implants were tunable based upon the number of coating bilayers and that release followed a power law dependence profile. In-vitro macrophage culture assays showed that implants coated with IL-4 promoted polarization to an M2 phenotype, demonstrating maintenance of IL-4 bioactivity following processing and sterilization. Finally, in-vivo studies showed that mice with IL-4 coated implants had increased percentages of M2 macrophages and decreased percentages of M1 macrophages at the tissue-implant interface during early stages of the host response. These changes were correlated with diminished formation of fibrotic capsule surrounding the implant and improved tissue integration downstream. The results of this study demonstrate a versatile cytokine delivery system for shifting early-stage macrophage polarization at the tissue-implant

\footnotetext{
*Corresponding author: Bryan N. Brown, Ph.D. Assistant professor. McGowan Institute for Regenerative Medicine, University of Pittsburgh. 450 Technology Drive, Suite 300. Pittsburgh, PA 15219. brownb@upmc.edu, Phone: 412-624-5273.

Publisher's Disclaimer: This is a PDF file of an unedited manuscript that has been accepted for publication. As a service to our customers we are providing this early version of the manuscript. The manuscript will undergo copyediting, typesetting, and review of the resulting proof before it is published in its final citable form. Please note that during the production process errors may be discovered which could affect the content, and all legal disclaimers that apply to the journal pertain.
} 
interface of a non-degradable material and suggest that modulation of the innate immune reaction at early stages of the host response may represent a preferred strategy for promoting biomaterial integration and success.

\section{Keywords}

Layer by layer coating; IL-4; surgical mesh; polypropylene; macrophage; foreign body reaction

\section{Introduction}

The host response to implanted materials begins immediately upon introduction of the material into the host tissue and encompasses multiple overlapping phases including injury, protein adsorption, acute inflammation, chronic inflammation, foreign body reaction, granulation tissue formation and eventual encapsulation [1]. It is well recognized that the early interactions which occur at the material-tissue interface represent the initiating events which drive subsequent paracrine and autocrine processes of the host response and subsequent tissue remodeling with significant implications for downstream performance. Recently, macrophage-implant interactions in particular have received considerable attention as a primary determinant of the outcome of biomaterials placement [2-7]. A spectrum of macrophage phenotypes contained between two extremes has been identified, ranging from pro-inflammatory (M1) to anti-inflammatory/regulatory (M2) phenotypes, with significant implications in disease, tissue remodeling following injury, and biomaterial performance [3, 8-12].

The findings of studies in multiple tissue and organ systems have now demonstrated that materials which elicit improved or regenerative remodeling outcomes are often associated with a shift from an initially M1 to a more M2-like profile during the early stages of the inflammatory response which follows implantation [13-18]. However, many of these studies have been performed as retrospective analyses of macrophage phenotypes associated with successful biomaterials. As a consequence, recent studies have now begun to evaluate improvements in regenerative outcomes following purposeful modulation of macrophage polarization induced by cytokine delivery from degradable materials [19-21]. These studies have demonstrated that outcomes are improved when M2-polarizing cytokines (IL-4, IL-10) are delivered and that, conversely, outcomes are negatively affected by the delivery of M1polarizing cytokines (IFN- $\gamma$ ) [19, 21, 22]. A recent study, however, showed that sequential delivery of an M1 (IFN- $\gamma$ ) and then an M2 (IL-4) polarizing cytokine enhanced the vascularity and subsequent healing response associated with the implantation of degradable bone scaffolds [21], demonstrating the importance of both the M1 and M2 responses in the remodeling process. Others have demonstrated that the host macrophage response is also important to the performance of permanent implants. For example, it has been demonstrated that wear particle-induced polarization of macrophages towards an M1 phenotype is associated with periprosthetic osteolysis, possibly resulting in the need for surgical revision following total joint replacement [23-26]. Subsequent studies demonstrated that methods including the delivery of inhibitors of macrophage recruitment, inhibitors of M1 polarization, and promoters of $\mathrm{M} 2$ polarization have the ability to mitigate wear particle 
induced osteolysis, potentially improving the long-term performance of total joint replacements [22, 27-29].

The present study sought to examine the effects of surface-localized cytokine delivery in the early macrophage response upon the integration of a non-degradable polypropylene mesh material commonly utilized in the repair of pelvic organ prolapse. These materials have recently been shown to elicit a predominantly M1 type response which is associated with the potential for tissue degradation and downstream complications when unresolved [30, 31]. Macrophage modulation only in early-stages of the host response, but also localized to the tissue-implant interface was sought in the present study, representing an advantage over strategies promoting non-local and/or extended shifts in the host response as it limits the potential for adverse long-term interactions and exacerbation of conditions which may exist at distant sites. Also, nanometer thickness of this coating was desired to preserve the architecture and pore space of the mesh, which is commonly thought to be important for adequate tissue ingrowth and mechanical performance in clinical settings [32, 33].

To accomplish these goals, a nanometer thickness multilayered coating able to control the release of IL-4 from polypropylene mesh in a localized and temporal manner was developed. This coating is based on the layer by layer (LbL) technique [34,35], consisting of an alternate cyclic deposition of multiple polyelectrolyte layers mediated by opposite electrostatic charges on the surface of a charged substrate. This method has previously been shown to produce a tunable, uniform and conformal coating of nanometer thickness for controlled release of proteins [27, 34-40]. Therefore, the number and sequence of layers can be easily modified in order to provide the desired amount and release time of IL-4.

\section{Methods}

Materials

A polypropylene mesh, Gynemesh ${ }^{\circledR}$ PS (Ethicon, Somerville, NJ) was used. Maleic anhydride, chondroitin sulfate $\mathrm{B}$, chitosan (low molecular weight, deacetylation degree 85\%), chondroitinase $\mathrm{ABC}$, chitosanase, bovine serum albumin (BSA) and histologic staining materials were purchased from Sigma Aldrich (St. Louis, MO). Murine IL-4, antimurine IL-4 antibody, murine IL-4 ELISA detection kit were purchased from Peprotech (Rocky Hill, NJ). Mouse arginase-1 antibody (rabbit), anti-rabbit Alexa-fluor 488 (donkey) and anti-rabbit Alexa-fluor 594 (donkey) were purchased from Abcam (Cambridge, MA). Mouse iNOS antibody (rabbit) was purchased from Santa Cruz (Dallas, TX). Mouse F4/80 antibody (rat) was purchased from AbD Serotec/Bio Rad (Raleigh, NC). Anti-rat Alexafluor 488 (donkey) and anti-rabbit Alexa-fluor 546 (donkey) were purchased from Thermo Fisher (Pittsburgh, PA).

\section{Plasma treatment of polypropylene meshes}

Polypropylene (PP) meshes were cleaned using a 1:1 acetone:isopropanol mixture and then air dried prior to irradiation with 15 seconds of argon plasma at $600 \mathrm{~W}$, an argon gas flow of $35 \mathrm{~mL} / \mathrm{min}$ and a steady state pressure of $250 \mathrm{mTorr}$ (50 mTorr initial pressure) using an Ion 40 Gas Plasma System (PVA Tepla America, Inc). 
An adapted radio frequency glow discharge (RFGD) based on a previously developed microwave plasma procedure was used to obtain a negatively charged surface [41]. Briefly, maleic anhydride powder ( $1.5 \mathrm{gr})$ was placed into a glass plate inside of the machine chamber. $1 \mathrm{~cm}^{2}$ pieces of PP mesh were then placed around the plate to a distance of $8.5 \mathrm{~cm}$. After an initial pressure of 50 mTorr was reached, 30 seconds of maleic anhydride plasma treatment was performed at $600 \mathrm{~W}$, an argon gas flow of $35 \mathrm{~mL} / \mathrm{min}$ and a steady state pressure of 250 mTorr. Finally, in order to remove the physisorbed maleic anhydride and to hydrolyze the anhydrides and produce carboxylic acid groups (negatively charged at physiological $\mathrm{pH}$ ), $\mathrm{PP}$ meshes were rinsed for 30 minutes with milli-Q water and then boiled for 20 minutes in fresh milli-Q water.

\section{Layer by Layer coating of charged polypropylene meshes}

In order to deposit a conformal coating of nanometer thickness onto the surface of negatively charged PP meshes, a Layer by Layer (LbL) procedure was performed (Figure 1). Chitosan was chosen as polycation and dermatan sulfate (chondroitin sulfate $\mathrm{B}$ ) as polyanion. Chitosan was dissolved in $0.5 \%$ acetic acid and dermatan sulfate in milli-Q water. Both polyelectrolites were prepared at a concentration of $2 \mathrm{mg} / \mathrm{mL}$. First, meshes were dipped in chitosan for 10 minutes at room temperature, then meshes were washed 3 times $(10,20$ and 30 seconds) in milli-Q water and air dried (pressurized clean air). Next, meshes were dipped in a dermatan sulfate solution for 10 minutes at room temperature. Meshes were washed again in milli-Q water and air-dried. This cycle was repeated until a core coating of 10 bilayers $\left(\mathrm{PP}^{-}[\mathrm{CH} / \mathrm{DS}]_{10}\right)$ was achieved. After coating, meshes were lyophilized and stored at $4^{\circ} \mathrm{C}$.

\section{IL-4 Loading of Coated PP Meshes}

Prior to IL-4 loading onto the meshes, an IL-4 $(1.5 \mu \mathrm{g} / \mathrm{mL})$ - dermatan sulfate $(2 \mathrm{mg} / \mathrm{mL})$ mixture was made and incubated overnight at $4^{\circ} \mathrm{C}$ in order to complex IL-4 into the polyanion. Then, polypropylene meshes with a 10-bilayer core coating were further coated with 20, 40 and 60 bilayers containing IL-4 ( $\mathrm{PP}^{-}[\mathrm{CH} / \mathrm{DS}]_{10}\left[\mathrm{CH} / \mathrm{DS}^{\mathrm{IL}-4}\right]_{\mathrm{x}}$, where $\mathrm{x}$ stands for number of bilayers, and $\mathrm{DS}^{\mathrm{IL}-4}$ stands for dermatan sulfate bound IL-4). After coating, IL-4 loaded meshes were lyophilized and stored at $-20^{\circ} \mathrm{C}$. Coated (no IL-4) meshes were used as controls, using the same numbers of bilayers used for IL-4 loaded meshes. All mesh materials were then terminally sterilized using ethylene oxide.

\section{Coating characterization}

An Alcian blue staining was performed on whole samples to stain the GAG components and reveal the coating. A $1 \%$ Alcian blue solution was made in 3\% acetic acid and adjusted to $\mathrm{pH}$ 2.5. Coated meshes and controls were re-hydrated in distilled water and then immersed into the Alcian blue solution for 30 minutes at RT. Then meshes were washed in running tap water for 5 minutes and rinsed 5 minutes in distilled water. Images were taken using a standard optical camera.

Additionally, elemental composition of the coated meshes was performed using an X-ray photoelectron spectroscopy (XPS), using an ESCALAB 250Xi, Thermo Scientific (Pittsburgh, PA). To identify the elements in the coating/surface of the meshes, an initial 
survey of 10 scans was obtained and for detailed elemental information, spectra of 25 scans were obtained for Carbon, Oxygen, Nitrogen and Sulfur. Spectra data was analyzed using Avantage software, Thermo Scientific.

Finally, meshes were analyzed under Fourier transform infrared spectroscopy with attenuated total reflectance (ATR-FTIR) using a Bruker Vertex 70 (Billerica, MA) equipped with a germanium ATR crystal at a resolution of $1 \mathrm{~cm}^{-1}, 2 \mathrm{~mm}$ of aperture, 32 scans and processed by OPUS software to adjust the baseline, to smooth spectra and to remove $\mathrm{H}_{2} \mathrm{O}$ and $\mathrm{CO}_{2}$ peaks due to environmental noise.

\section{IL-4 loading and release assays}

Immunolabeling was used to qualitatively demonstrate the loading and distribution of IL-4 throughout the coating. IL-4 loaded, coated (no IL-4) and pristine meshes were immersed in a $1 \%$ BSA solution to block non-specific adsorption of antibodies (1h, RT). Washing was performed in between each step by dipping the meshes 4 times in $0.05 \%$ Tween 20 . Then meshes were immersed and incubated in a solution of anti-murine IL-4 (from rabbit) as primary antibody ( $1: 100$ in $0.1 \%$ BSA, 2 hours, RT). Meshes were then immersed in a solution of anti-rabbit-Alexa Fluor 546 as a secondary antibody (1:100 in $0.1 \%$ BSA, 30 min, RT). Mesh fluorescence was observed under confocal microscopy (Leica DMI4000 B, Buffalo Grove, IL), in which an excitation/emission of $480 / 520 \mathrm{~nm}$ was used to observe the mesh autofluorescence (green) and 561/572 nm to observe the specific fluorescence due to the loaded IL-4 (red).

Loading efficiency and release assays were performed following manufacturer instructions of the Peprotech IL-4 ELISA kit. First, $1 \mathrm{~cm}^{2}$ pieces of IL-4 loaded (20, 40 and 60 bilayers) and coated (no IL-4) meshes were immersed into $400 \mu \mathrm{L}$ of a solution 0.05 units $/ \mathrm{mL}$ chondroitinase $\mathrm{ABC}$ and 0.05 units $/ \mathrm{mL}$ chitosanase in $1 \mathrm{X}$ PBS. Incubation was performed to multiple time points at $37^{\circ} \mathrm{C}$, after which $400 \mu \mathrm{L}$ of solution were aliquoted and stored at $-80^{\circ} \mathrm{C}$ until the end of the experiment. After collection, replacement with fresh solution was performed to continue the release assay. To perform the ELISA assays, $100 \mu \mathrm{L}$ aliquots were used from each sample $(\mathrm{N}=9)$ at each time point.

To determine release profile kinetics; correlation and curve fitting analyses were performed using the data from cumulative release versus time, until the first time point where the release reaches a plateau, which corresponds to the total release. To corroborate power law dependence, besides direct curve fitting tests, a linear trend was corroborated using a LOG (cumulative release) versus LOG (time) curve.

\section{In-vitro macrophage culture assay}

An in-vitro macrophage culture assay was performed in order to demonstrate preservation of bioactivity of IL-4 released from the coated meshes. Bone-marrow mononuclear cells were obtained from murine bone marrow as previously described [42], then these cells were seeded in plates and differentiated to macrophages with DMEM, 10\% FBS, 10\% L929 supernatant, 1\% HEPES, 2\% MEM NEAA, 0.1\% $\beta$-2-mercaptoethanol (Sigma Aldrich, St. Louis, MO) for 7 days. $5 \times 10^{5}$ cells were plated into 24-well plates with a-MEM, $10 \%$ FBS, 0.05 units $/ \mathrm{mL}$ of both chondroitinase $\mathrm{ABC}$ and chitosanase. Macrophages were 
exposed to $1 \mathrm{~cm}^{2}$ pieces of pristine, coated (no IL-4) and IL-4 loaded (40 bilayers) meshes. Immunolabeling isotype (rabbit IgG) and soluble IL-4 (20 ng/mL) were used as negative and positive controls, respectively. Cells were incubated at $37^{\circ} \mathrm{C}$ and $5 \% \mathrm{CO}_{2}$ for 72 hours. After incubation, cells were fixed with 2\% PFA and then blocked with $2 \%$ horse serum, $1 \%$ BSA, $0.1 \%$ triton $\mathrm{X}-100,0.1 \%$ tween-20 for 1 hour at RT. Immunolabeling was performed using anti arginase- 1 as primary antibody $\left(1: 200\right.$, overnight at $\left.4^{\circ} \mathrm{C}\right)$ and Alexa Fluor-488 $(1: 300,1$ hour at RT) as secondary. A $500 \mathrm{nM}$ DAPI solution was used stain nuclei. Images were taken in an array of $3 \times 3$ images per each well using a Carl Zeiss Observer.Z1 microscope and then the intensity of arginase-1 staining was analyzed using Cell Profiler Image Analysis Software (Broad Institute, Cambridge, MA) using the same number of cells for all tested conditions.

\section{In-vivo mouse mesh implantation}

An implantation model using C57BL/6J female mice, 8 - 10 weeks old was used, following proper housing and treatment procedures approved by the Institutional Animal Care and Use Committee (IACUC) of the University of Pittsburgh and the National Institutes of Health Guide for the Care and Use of Laboratory Animals. A power analysis was performed to determine that 7 animals per group was required to maintain a statistical power of $80 \%$.

Briefly, a midline incision was made and a subcutaneous pocket was created in the abdomen of each mouse in order to implant a $1 \mathrm{~cm}^{2}$ piece of pristine, coated (no IL-4) and IL-4 loaded (40 bilayers) meshes. PCL sutures were used to close the incision, then $0.5 \mathrm{mg} / \mathrm{kg}$ of Baytril and $0.2 \mathrm{mg} / \mathrm{kg}$ of Buprenex were administered for 3 days as antibiotic and analgesic, respectively. Buprenorphine (Buprenex), an opioid analgesic, has been studied and shown not to exert any effects nor alterations in the immunological response, both acutely and chronically administered [43, 44]. After 7,14 or 90 days, mice were euthanized and skin/ $\mathrm{mesh} / \mathrm{muscle}$ tissue complex were harvested and fixed for 72 hours in neutral buffered formalin. Finally, fixed tissues were paraffin embedded and cross-sections of $7 \mu \mathrm{m}$ were used for histological studies.

\section{Immunolabeling of histological sections}

Paraffin embedded tissue sections were deparaffinized and hydrated in a series of xylene/ alcohol/water. Incubation with proteinase $\mathrm{K}(1 \mathrm{X})$ for 10 minutes at $37^{\circ} \mathrm{C}$ was performed to retrieve antigens. After 3 washes in water, samples were incubated at $37^{\circ} \mathrm{C}$ in $50 \mathrm{mM}$ of $\mathrm{CuSO}_{4}$ in $10 \mathrm{mM} \mathrm{NH}_{4} \mathrm{Ac}$ buffer $\mathrm{pH}=5$, to reduce tissue background fluorescence. Slides were washed twice in TBST ( $25 \mathrm{mM}$ Tris buffer $+0.1 \%$ tween 20 ). Then, a $5 \%$ donkey serum $+2 \% \mathrm{BSA}+0.1 \%$ tween $20+0.1 \%$ triton $\mathrm{X}-100$ solution was used as blocking agent (2 hours, RT). To immunolabel M2 macrophages, arginase-1 (1:100) and F4/80 (1:50) primary antibodies were used (overnight at $4{ }^{\circ} \mathrm{C}$ ), followed by anti-rabbit Alexa Fluor 594 (1:200) and anti-rat Alexa Fluor 488 (1:100) secondary antibodies (40 min at RT) in blocking buffer. To immunolabel M1 macrophages, iNOS (1:100) and F4/80 (1:50) primary antibodies were used (overnight at $4{ }^{\circ} \mathrm{C}$ ), followed by anti-rabbit Alexa Fluor 594 (1:100) and anti-rat Alexa Fluor 488 (1:100) secondary antibodies (40 min at RT) in blocking buffer. Vectashield with DAPI mounting media (Vector laboratories, Burlingame, CA) was used to stain nuclei and mount. Images of centered single fibers (3 different single fibers per sample, 
$\mathrm{N}=8$ each group) were taken on a Nikon Eclipse E600 microscope equipped with epifluorescence at $40 \mathrm{X}$ and cell counts were analyzed using ImageJ (version 1.51a, NIH).

Image analysis algorithms were used to quantify the results obtained by imaging of histological tissue sections. First, a custom-designed algorithm (Wolfram Mathematica, version 10.0. Champaign, IL) was used to quantify both arginase-1 and iNOS expression at 7 and 14 days by means of arginase-1/DAPI and iNOS/DAPI pixel ratio versus the distance from the surface of single centered mesh fiber ( 3 different single fibers, $\mathrm{N}=8$ each group) images taken from histological tissue sections per sample. Next image analysis was performed using ImageJ (version 1.51a, NIH) in order to quantify the number of proinflammatory (iNOS, M1) and regulatory (arginase-1, M2) macrophages (F4/80) surrounding single mesh fibers in each group.

\section{Histological stainings}

Paraffin embedded tissue cross-sections were used for H\&E, Masson's trichrome and Picro Sirius Red staining. H\&E and Masson's trichrome stained tissue sections were imaged on a Nikon Eclipse E600 microscope (Tokyo, Japan) at 10X and 20X, respectively. Picro Sirius Red stained tissue sections were imaged at 20X on a Nikon Eclipse TE2000-E (Tokyo, Japan), equipped with circularly polarized light.

ImageJ (version 1.51a, NIH) equipped with a color deconvolution plug-in (version 1.5) was used to quantify the area and mean thickness (calculated as the mean of apical, basal, and lateral measurements taken perpendicular to the surface of the mesh fiber, Figure S1) of capsule surrounding mesh fibers at 90 days ( 3 different single fibers per sample, $\mathrm{N}=8$ each group) in images taken from histological tissue sections stained with Masson's Trichrome.

A custom-designed algorithm (Mathworks MathLab, version R2015a. Natick, MA) was used to evaluate quantitatively the distribution of collagen fiber sizes surrounding mesh fibers at 90 days ( 3 different single fibers per sample, $\mathrm{N}=8$ each group) in images taken from histological tissue sections stained with Picro Sirius Red.

\section{Statistical Analysis}

Comparisons of means were performed by either one-way or two-way analysis of variance (ANOVA), using at least $\mathrm{p}<0.05$ as statistical significance criteria followed by Tukey's test to compare groups and Sidak's test to compare time points. Shapiro-Wilk was used to test normality. All statistical tests were performed on GraphPad Prism V7 (La Jolla California, USA).

\section{Results and Discussion}

\section{Surgical mesh plasma irradiation, LbL coating and characterization}

An adapted radio frequency glow discharge (RFGD) method [41] was used to form a consistent and durable negative charge on the surface of polypropylene (PP) mesh in order to facilitate the desired LbL coating. The presence of a negatively charged surface was confirmed by the appearance of two peaks at $284 \mathrm{eV}(\mathrm{C}-\mathrm{C})$ and $288 \mathrm{eV}(\mathrm{O}-\mathrm{C}=\mathrm{O})$ on the carbon spectrum and a peak at $532 \mathrm{eV}$ on the oxygen spectrum, while pristine mesh only had 
a peak at $284 \mathrm{eV}$ (C-C) when evaluated by X-ray photoelectron spectroscopy (XPS) (Figure 2a). RFGD treated meshes were then LbL coated using chitosan as a polycation and dermatan sulfate as a polyanion. Chitosan was chosen for its known biocompatibility, antimicrobial activity, and as activated macrophages highly express chitinase-like proteins (chitin and chitosan degrading enzymes) [45-47]. Dermatan sulfate (also known as chondroitin sulfate B) was chosen for its key role in extracellular matrix (ECM) regulation and its described ability to enhance IL-4 bioactivity in-vivo [48]. Thus, a chitosan-dermatan sulfate LbL complex has the potential to provide enhanced release and bioactivity of IL-4 in the context of macrophage mediated host-implant interactions.

A coating of 10 bilayers was performed as core coating prior to IL-4 loading. Alcian blue staining was used to visualize the chitosan and dermatan sulfate components of the coating. Blue coloration and absence of precipitates along the mesh surface suggested the presence of a conformal and uniform coating on LbL coated meshes (Figure 2b). Electron microscopy (Figure 3) was used to confirm the conformal nature of the coating and showed no apparent changes in surface topography, porosity and thickness between LbL coated, RFGD treated and pristine meshes. The presence of chitosan in the LbL coating was corroborated by the appearance of two peaks at $399 \mathrm{eV}(\mathrm{C}-\mathrm{N})$ and $401 \mathrm{eV}(\mathrm{O}-\mathrm{C}-\mathrm{N})$ in the nitrogen spectrum and the presence of dermatan sulfate by the appearance of a peak at $168 \mathrm{eV}$ (C-S-O) in the sulfur spectrum when evaluated by XPS (Figure 2a), in addition to the presence of peaks at $288 \mathrm{eV}$ $(\mathrm{O}-\mathrm{C}=\mathrm{O})$ and $286 \mathrm{eV}(\mathrm{C}-\mathrm{O})$ in the carbon spectrum, confirming the presence of both polyelectrolyte chains. These measurements were performed at different points on the surface of the PP mesh and spectra were identical throughout the mesh surface. These findings were consistent with ATR-FTIR measurements (Figure S2).

\section{IL-4 loading, release and bioactivity assessments}

Mesh coated with a 10-bilayer core coating was then coated with 20, 40 and 60 additional bilayers containing IL-4. IL-4 was pre-incubated with dermatan sulfate prior to LbL coating, promoting the loading of the cytokine due to the high affinity of IL-4 (net positive charge, given its isoelectric point of 9.17) for sulfated glycosaminoglycans (negatively charged). Confocal microscopy demonstrated positive IL-4 labeling distributed throughout the entire surface of IL-4 loaded meshes in contrast to the absence of positive labeling on coated (no IL-4) mesh and pristine mesh (Figure 4a). ELISA assays were performed to quantify IL-4 release over time. Results showed that both the amount of IL-4 and the length of release are dependent on the number of bilayers containing IL-4 in the LbL coating (Figure 4b). In particular, the in vitro release of IL-4 was observed up to 14, 22 and 30 days for coatings of 20, 40 and 60 bilayers, respectively. The release profile for all IL-4 loaded meshes followed a power law dependence, regardless of the number of coating bilayers (Figure $4 \mathrm{c}$ ). These findings are consistent with other studies done on LbL films as a platform to study protein release $[36,37,40]$. Based upon these results, meshes coated with 40 bilayers containing IL-4 were selected for further in-vitro and in-vivo assays, since the coating released about $90 \%$ of IL-4 only at early stages of the host response (up to 14 days). All further assays included coated (40 additional bilayers with no IL-4) and pristine mesh groups as control groups. 
In order to show that IL-4 bioactivity remained after the coating procedure and terminal sterilization by ethylene oxide, an in-vitro macrophage polarization assay was performed using mouse bone marrow-derived macrophages. Macrophages exposed to IL-4 loaded meshes for 72 hours were fixed and immunolabeled against arginase-1, an M2 macrophage specific marker. Image analysis (CellProfiler, Broad Institute, Cambridge, MA) of arginase-1 positive cells revealed that the IL-4 released from the IL-4 loaded mesh remained bioactive and able to polarize macrophages towards an M2 phenotype (Figure 5). No significant increase of arginase-1 was observed for coated mesh compared to pristine mesh. Of note, the pattern of arginase-1 expression following exposure to IL-4 coated meshes was similar to the IL-4 positive control $(20 \mathrm{ng} / \mathrm{mL})$ despite the lower levels of IL-4 $(2.25 \mathrm{ng} / \mathrm{mL})$ released from the mesh surface at $72 \mathrm{~h}$ (Figure $5 \mathrm{~d}$ ), suggesting that the coating components may enhance IL-4 bioactivity or that IL-4 is protected by the coating and released gradually.

\section{Studies on macrophage polarization and the early-stage host response against implanted mesh}

A mouse implantation model was used to test the ability of IL-4 loaded mesh to promote an early shift ( 7 and 14 days) in the polarization of macrophages towards an M2 phenotype invivo and to examine the effects of such shifts in macrophage polarization upon downstream tissue remodeling (90 days). $1 \mathrm{~cm}^{2}$ of pristine mesh, coated (no IL-4) mesh and IL-4 loaded mesh (40B) were implanted into a subcutaneous pocket in the abdomen of 8-10 week old female C57BL/6J mice. Mesh and surrounding tissue (muscle and skin) were then harvested at 7 and 14 days post-implantation and used to study macrophage polarization. Sham surgeries (no mesh implantation) were also performed. In sham animals, a normal wound healing process observed (Figure 6, top panel) and was characterized by a transient inflammatory response including significant immune cell infiltration at 7 days which was largely resolved by 14 days post-inflammation with restoration of normal tissue architecture resembling healthy tissue controls. The histologic appearance in mice implanted with mesh was also characterized by the presence of inflammatory cell infiltration in the surgical site at 7 days; however, this reaction was not resolved at 14 days and was largely localized to the area surrounding mesh fibers, regardless of mesh type (Figure 6, bottom panel), thereafter. The presence of foreign body giant cells was noted beginning at 14 days post implantation and at the 90 day time point, regardless of mesh type. While the number and distribution of foreign body giant cells was qualitatively similar across all groups, no attempt was made in the present study to quantify the number of foreign body giant cells.

Immunolabeling of F4/80 (pan macrophage marker), arginase-1 (an M2 marker) and inducible nitric oxide synthase (iNOS, an M1 marker) was performed to assess the number, location, and phenotypic profiles of the macrophages within the site of implantation at 7 and 14 days (Figure $7 \mathrm{a}, \mathrm{c}$ ). In all mesh groups, the number of both arginase- 1 and iNOS positive cells was observed to peak within the first $50 \mu \mathrm{m}$ from the mesh surface (Figure $7 \mathrm{~b}, \mathrm{~d}$ ). Therefore, this distance was considered as the tissue-biomaterial interface, where the most important interactions of the biomaterial with the surrounding tissue occur and determine the implant success in the long term. 
Total cell infiltration around single mesh fibers was assessed by DAPI staining, revealing no differences between groups at 7 or 14 days (Figure 8a). However, the small increases in the number of cells within the remodeling site were observed from 7 to 14 days in the pristine and IL-4 loaded mesh implantation groups. Analysis of F4/80 revealed a significantly higher presence of $\mathrm{F} 4 / 80^{+}$cells as a percentage of the total cell population in mice implanted with pristine mesh, compared to both coated (no IL-4) and IL-4 loaded mesh groups at 7 days (Figure 8b). At 14 days, the percentage of $\mathrm{F} 4 / 80^{+}$cells in the pristine mesh group was significantly reduced and was similar to levels similar to those found in both coated (no IL-4) and IL-4 loaded meshes. The percentage of F4/80 $0^{+}$cells in the implantation site of IL-4 loaded meshes were also significantly decreased compared to 7 days, but these decreases were smaller than those observed for the pristine mesh group. There were no differences in the percentage of $\mathrm{F} 4 / 80^{+}$cells between coated (no IL-4) and IL-4 loaded mesh groups at 7 or 14 days. These results suggest that the coating may have had an inhibitory effect upon the recruitment of macrophages into the implantation site at early time points.

Additional co-labeling was performed for arginase-1 and iNOS to assess the M1/M2 polarization profile of the cells within the implantation site. Results at 7 days postimplantation revealed that mice implanted with IL-4 loaded mesh were associated with an increased percentage of Arg- $1^{+}$macrophages $\left(\mathrm{F} 4 / 80^{+}\right)$as compared to both coated mesh and pristine mesh groups (Figure 8c). The difference in arginase-1 labeling in the IL-4 loaded mesh group was greatest in the first 40 to $50 \mu \mathrm{m}$ from the mesh surface (Figure $7 \mathrm{~b}$ ) as compared to both coated and pristine mesh, suggesting that the effects of IL-4 released from the LbL coating are limited to distances up to $50 \mu \mathrm{m}$ from the surface of the implanted mesh. Coated mesh did not elicit an increase in Arg- $1^{+}$macrophages as compared to pristine mesh (Figure 8c). These results are consistent with the in-vitro findings showing significant increases in M2 macrophage polarization only in the IL-4 loaded mesh group (Figure 5). Results at 7 days post-implantation also showed a reduction of iNOS ${ }^{+}$macrophages in mice implanted with IL-4 loaded meshes compared to mice implanted with pristine meshes (Figure 8d). Mice implanted with coated mesh also showed a reduction in iNOS ${ }^{+}$ macrophages compared to the pristine mesh implanted group; however, no significant differences were observed between the coated mesh and IL-4 loaded groups (Figure 8d). These results suggest that the coating material may have impacted the polarization of macrophages towards an M1 profile. Differences in iNOS labeling were observed to peak at $25 \mu \mathrm{m}$ from the mesh surface of the pristine mesh implanted group at 7 days (Figure 7d), again suggesting that the effects of the coating were limited to the first $50 \mu \mathrm{m}$ from the mesh surface.

Results at 14 days post-implantation revealed a decrease in Arg- $1^{+}$macrophages in mice implanted with IL-4 mesh as compared to the 7 day time point; however, the percentage of Arg- $1^{+}$macrophages was still higher than both coated (no IL-4) and pristine mesh groups (Figure 8c). The percentage of iNOS ${ }^{+}$macrophages at 14 days was found to decline in mice implanted with pristine mesh as compared to 7 days; however, there were no significant differences observed between any groups at the 14 day time point (Figure 8d). When the effects of IL-4 coating upon the percentage of Arg- $1^{+}$macrophages at 7 and 14 days were compared (Figure 8c) it can be appreciated that arginase-1 expression in the IL-4 coated 
group at 14 days returned to levels similar to those observed for pristine mesh at both 7 and 14 days. This suggests that the length of IL-4 release from the LbL coated meshes occurs mostly at early stages of the host response $(<14$ days) and that its effects on macrophage polarization in-vivo are declining by 14 days.

While increases in the M2 macrophage population can likely be attributed to the release of IL-4 from loaded mesh as demonstrated in vitro, there are two potential rationales for the observed reduction in the number of $\mathrm{NOS}^{+}$macrophages in the IL-4 loaded mesh group. First, iNOS expression may be reduced as a consequence of the polarization of the macrophages at the tissue implant interface towards an M2 phenotype, given the known competitive nature of pathways leading to iNOS and arginase-1 expression in mice [49-51]. Second, decreased percentage of iNOS $^{+}$macrophages may be due to the effects of the coating components and/or surface plasma treatment upon macrophage polarization. This second mechanism is supported by the significant reduction in the percentage of iNOS $^{+}$ macrophages (Figure 8d) but also a reduction in $\mathrm{F} 4 / 80^{+}$cells (Figure 8b) observed in the coated mesh group at 7 days. Therefore, the coating components and/or modified mesh surface themselves appear to have effects in the reduction of M1 macrophages but not in promoting M2 macrophage polarization. Thus, the observed results are likely a combination of mechanisms driving the reduction of M1 macrophages with IL-4 mediated increases in the M2 population.

We noted that some Arg- $1^{+}$and iNOS $^{+}$cells did not express F4/80. This suggests cells other than macrophages may produce Arg-1 and iNOS in the area of implantation, or that a population of macrophages which express other markers such as CD11b or CD68 but not F4/80 are present within the remodeling site. Supplemental Figure 3 shows the percentage of total cells expressing Arg-1 and iNOS co-labeled with F4/80, and Supplemental Figure 4 shows the percentage of total cells expressing only Arg-1 or iNOS.

\section{Downstream effects in the host response upon macrophage polarization promoted by implanted meshes}

Mesh and the surrounding tissue complex were harvested at 90 days post-implantation to evaluate the effects of mesh coating and IL-4 loading upon long-term tissue remodeling outcomes. Image analysis of Masson's trichrome stained histological sections was performed to identify and quantify capsule formation. Results revealed capsule formation around mesh fibers for all groups (Figure 9a); however, IL-4 loaded mesh elicited reduced capsule area and thickness compared to the prominent and dense capsules surrounding fibers of both coated and pristine meshes (Figure $9 \mathrm{~b}, \mathrm{c}$ ). Subsequent analysis of collagen fiber distribution in picrosirius red stained sections was performed using a custom-designed algorithm (Mathworks MatLab R2015a). Circularly polarized light microscopy was able to reveal the relative thickness of the collagen fibers as a function of the color hue from thin green fibers to increasingly thick yellow, orange and red fibers [52]. Results revealed that mice implanted with IL-4 loaded meshes had reduced content of both thick orange and thicker red collagen fibers, compared to both pristine and coated meshes (Figure 10). A concurrent increase in thin yellow and thinner green collagen fibers was found for IL-4 loaded mesh compared to both pristine and coated mesh. While we note that the tissue remodeling process is 
incomplete at the 90 day time point, these outcomes indicate a change in the quantity and type of the collagen fibers composing the fibrotic capsule. These findings may be relevant to potential improvements in mechanical performance of the implanted mesh in-vivo, and are the subject of future studies.

The results of the present study demonstrate that the release of IL-4 from LbL coated mesh promotes shifts in early-stage macrophage polarization that are associated with positive long-term effects such as minimized capsule formation and improved tissue quality and composition compared to coated and pristine meshes. These results also suggest that longterm positive outcomes are due to an early-stage increase in the proportion of M2 macrophages, rather than a decrease in the presence of M1 macrophages or total F4/80+ macrophages, given that coated meshes were also capable of significantly decreasing the proportion of M1 macrophages and $\mathrm{F} 4 / 80^{+}$macrophages (Figure 7,8 ) as compared with pristine mesh, but were not associated with improved tissue remodeling outcomes (Figure 9, 10). The present study also clearly demonstrates that it is possible to transiently shift the early phases of the host response to implants which otherwise elicit a chronic proinflammatory response with significant impact upon the tissue remodeling outcome downstream while leaving key implant characteristics such as material properties and porosity intact.

It has been previously suggested that excessive long-term polarization towards either an M1 or an M2 phenotypes may have negative effects on remodeling outcomes [3, 13, 53]. Additionally, an increasing number studies have described pathologies associated with an imbalance and long-term presence of M1 or M2 macrophages, including but not limited to cancer, diabetes and atherosclerosis $[12,54,55]$. Therefore, localized and temporal delivery of bioactive agents represents an advantage over strategies promoting systemic and or permanent shifts in the host response as it limits the potential for adverse long-term interactions and exacerbation of conditions which may exist at distant sites. Similarly, promoting transient shifts in macrophage polarization in the early host response represents an improved approach as compared to strategies which seek to evade the host immune response. Previous studies using surface modification of biomaterials and coatings to escape the innate immune system have shown only modest improvements at early stages of the host response against biomaterials and few improvements in long-term performance [56-60]. Finally, the present delivery system represents an advantage over previous delivery approaches, given that significant effects on macrophage polarization are observed at lower, controllable and safer doses (picograms to nanograms), compared to the high doses (nanograms to micrograms) of IL-4 used in previous studies [19, 21, 22]. The systemic release of larger amounts IL-4 may lead to effects upon distal tissues and/or exacerbated and contradictory outcomes associated with a fibrotic process or potential enhancement of the foreign body reaction $[61,62]$.

At present, the stability of the coating and release profile of IL-4 in vivo is unknown. Alcian blue labeling, which as used to identify the coating in vitro, was used to attempt to identify the coating in histologic sections. The presence of the coating was indistinguishable at any time point which we evaluated in the present study. The lack of Alcian Blue staining around the fibers, however, does not necessarily indicate that the coating is degraded. As the coating 
is on the nanometer scale, it may not be possible to distinguish the staining using routine histologic methods. In-vivo, both the chitosan and dermatan sulfate components of the coating are mostly degraded by macrophages and other cells participating in the host response. Layer by layer films have shown multiple release mechanism, depending the nature of the polyelectrolytes composing the films, being surface degradation the most predominant mechanism that gradually releases the entrapped bioactive agents by degradation of the most external layer films, followed by more internal layers [63, 64]. Therefore, IL-4 is most likely released by gradual surface degradation of the coating multilayers, mainly triggered by macrophages and other cells of the immune system with enzymatic capacity. However, release by diffusion of IL-4 may also occur to a lesser extent. Additional follow up studies should be performed to specifically address in-vivo release profiles.

There were several limitations to the present study. First, while the present study demonstrated positive results from the use of IL-4 as a macrophage polarizing molecule, it should be noted that multiple IL-4 isoforms do exist with potentially different functional effects $[65,66]$. The IL-482 isoform of IL-4, for example, has been shown to promote the expression of multiple pro-inflammatory cytokines and the chemotaxis of $\mathrm{T}$ and $\mathrm{B}$ cells [66]. Thus, careful consideration of the exact formulation and potential adverse effects of the IL-4 containing coating is necessary. Further, it is well known that these pathways and others, including IL-4, are regulated differently in humans and mice [65, 67, 68]. Thus, additional testing must be performed to demonstrate potential relevance to human conditions. The LbL method described in the present manuscript is amenable to the use of other macrophage polarization inducing molecules and alternative molecules can likely be substituted for IL-4 if needed for further development.

Second, the present study the primary metric of macrophage polarization was the Arg/iNOS percentage relative to $\mathrm{F} 4 / 80^{+}$macrophages. While the results of the present study clearly demonstrate a shift in macrophage phenotype at the host-material interface, surface marker labeling is not sufficient to fully characterize the phenotype of the macrophage population. Thus, further investigation is needed to clearly define the resultant phenotype and the potential paracrine mechanisms by which the observed shifts in macrophage phenotype affect the remodeling process. Increases in total cellularity were observed between the 7 and 14 day time points. While these increases were moderate, they were often also accompanied by a decrease in the $\mathrm{F} 4 / 80^{+}$cell population, suggesting a replacement of the macrophages by other cells. These changes could be associated with recruitment of fibroblasts and other cells involved in late phases of the host response.

Studies in both the biomaterials and wound healing literature have shown complex and reciprocal cell-cell crosstalk between macrophages and fibroblasts during the processes of healing and fibrosis [69-72]. In the context of the foreign body reaction, these interactions have been shown to result in increased expression of MCP-1 (a potent recruiter of macrophages and a mitogen for fibroblasts), the inhibition of macrophage secretion of cytokines, and the promotion of fibroblast production of cytokines, among others [71]. Thus, the potential effects of IL-4 upon fibroblasts and subsequent effects upon macrophages and other immune cells are important and should also be considered. Further, it has been shown 
that macrophages can also drive fibroblasts to form multinucleated cells in-vitro, resembling some characteristics of the foreign body giant cells [72]. The exact implications of such findings and their role in the present study are unknown, but warrant further examination to determine the specific effects of IL-4 coatings upon both macrophages and other cells participating in the remodeling process.

Third, in the present study, the evaluation of macrophage phenotype was performed in the area of single fibers in order to simplify quantification of macrophage numbers as well as downstream histologic outcomes around a complex shape. However, we note that recent published studies have demonstrated that density of the mesh is a local driver of the host macrophage response, where increased local mesh density is associated with an increased local pro-inflammatory response [30,31]. While investigation of the differences in the host response between fibers and knots was beyond the scope of the present study, it will be important to evaluate the effects of IL-4 coated mesh knots in order to illustrate the effects in the host response of the released IL-4 and the coating in the presence of high density and complex geometry of the implant.

Fourth, the host inflammatory response is also known to be variable by tissue location and context. Of particular relevance to the present study, the host response to polypropylene mesh in the vagina has been reported to be significantly different than that in the abdominal wall musculature $[30,73]$. Thus, testing of the present strategy in more relevant model systems must be performed to demonstrate utility in these applications. Additionally, the present study used only one concentration of IL- 4 and only investigated 40 bilayers of IL-4 loaded coating. Further studies will be necessary to determine the ideal number of coating layers and optimal time of release. Ideally, the smallest dose of IL-4 and shortest time of release should be identified to reduce the potential for systemic effects of IL-4 release.

Finally, the mechanism by which shifts in macrophage phenotype drives improved implant integration have yet to be identified. While it is logical that the presence of a chronically activated M1 macrophage population at the tissue-implant interface would lead to tissue degradation or encapsulation in the long term, it is unclear how M2 macrophages affect the tissue remodeling process and whether M1 macrophages play any essential role in the early remodeling phase (i.e. phagocytosis, activation of local cell populations, production of chemotactic signals). It is likely that both M1 and M2 macrophages play important roles in tissue remodeling, and that the timing of the phenotypic switch will prove an essential factor in determining the degree of success.

\section{Conclusions}

The presence of a uniform and conformal coating composed of both chitosan and dermatan sulfate is demonstrated. This coating can be loaded with IL-4 in a uniform manner through the entire surface of the mesh, and the amount and length of release can be tuned by simply changing the number and sequence of coating bilayers. The released IL-4 from LbL coated meshes is bioactive and can promote macrophage polarization towards an M2 phenotype both in-vitro and in-vivo. In addition, the effects of the local released IL-4 from LbL coated meshes on macrophage polarization extend up to $50 \mu \mathrm{m}$ of distance from the mesh surface 
only at early stages of the host response against biomaterials. At long term, a decreased fibrotic capsule formation surrounding mesh fibers and an improved quality of collagen fibers composing the capsule observed only in mice implanted with IL-4 loaded meshes indicating improved resolution of the foreign body reaction and subsequent tissue remodeling process.

Finally, these results are strong evidence to support our hypothesis that early-stage macrophage polarization at the tissue-implant interface towards an M2 phenotype would mitigate the foreign body reaction and hence promote better integration of non-degradable biomaterials into the host tissue in the long term. While the present study focused only upon polypropylene mesh commonly used for soft tissue reconstruction, the methods and findings presented can likely be extended to include other material types and applications.

\section{Supplementary Material}

Refer to Web version on PubMed Central for supplementary material.

\section{Acknowledgments}

Thanks to Rahul Rege and Yuta Umeda (undergraduate students, Bioengineering Department, University of Pittsburgh) for helping with the coating process. Immunolabeling custom-designed algorithm (Wolfram Mathematica, V10.0) was developed by William Barone, Ph.D., Department of Bioengineering, University of Pittsburgh. Picro Sirius Red custom-designed algorithm (MathWorks MathLab, VR2015a) was developed by Christopher Carruthers, Ph.D., Department of Bioengineering, University of Pittsburgh. Thanks to Dr. Pamela Moalli (Women's Research Institute, University of Pittsburgh) for the guidance throughout the course of the study. This work was performed, in part, at the Nanoscale Fabrication and Characterization Facility, a laboratory of the Gertrude E. and John M. Petersen Institute of NanoScience and Engineering; and the Center for Biologic Imaging, both housed at the University of Pittsburgh.

Funding: This work was supported by the National Institutes of Health [grant numbers K12HD043441 and R21GM107882].

\section{References}

1. Anderson JM, Rodriguez A, Chang DT. Foreign body reaction to biomaterials. Seminars in immunology. 2008; 20(2):86-100. [PubMed: 18162407]

2. Brown BN, Badylak SF. Expanded applications, shifting paradigms and an improved understanding of host-biomaterial interactions. Acta Biomater. 2013; 9(2):4948-55. [PubMed: 23099303]

3. Brown BN, Ratner BD, Goodman SB, Amar S, Badylak SF. Macrophage polarization: an opportunity for improved outcomes in biomaterials and regenerative medicine. Biomaterials. 2012; 33(15):3792-802. [PubMed: 22386919]

4. Miron RJ, Bosshardt DD. OsteoMacs: Key players around bone biomaterials. Biomaterials. 2016; 82:1-19. [PubMed: 26735169]

5. Barbeck M, Motta A, Migliaresi C, Sader R, Kirkpatrick CJ, Ghanaati S. Heterogeneity of biomaterial-induced multinucleated giant cells: Possible importance for the regeneration process? J Biomed Mater Res A. 2016; 104(2):413-8. [PubMed: 26422451]

6. Anderson JM, Jones JA. Phenotypic dichotomies in the foreign body reaction. Biomaterials. 2007; 28(34):5114-20. [PubMed: 17706278]

7. Bryers JD, Giachelli CM, Ratner BD. Engineering biomaterials to integrate and heal: the biocompatibility paradigm shifts. Biotechnology and bioengineering. 2012; 109(8):1898-911. [PubMed: 22592568]

8. Xue J, Schmidt SV, Sander J, Draffehn A, Krebs W, Quester I, De Nardo D, Gohel TD, Emde M, Schmidleithner L, Ganesan H, Nino-Castro A, Mallmann MR, Labzin L, Theis H, Kraut M, Beyer 
M, Latz E, Freeman TC, Ulas T, Schultze JL. Transcriptome-based network analysis reveals a spectrum model of human macrophage activation. Immunity. 2014; 40(2):274-88. [PubMed: 24530056]

9. Mosser DM, Edwards JP. Exploring the full spectrum of macrophage activation. Nature reviews. Immunology. 2008; 8(12):958-69.

10. Brown BN, Sicari BM, Badylak SF. Rethinking regenerative medicine: a macrophage-centered approach. Frontiers in immunology. 2014; 5:510. [PubMed: 25408693]

11. Murray PJ, Wynn TA. Protective and pathogenic functions of macrophage subsets. Nature reviews. Immunology. 2011; 11(11):723-37.

12. Mills CD. M1 and M2 Macrophages: Oracles of Health and Disease. Critical reviews in immunology. 2012; 32(6):463-88. [PubMed: 23428224]

13. Brown BN, Londono R, Tottey S, Zhang L, Kukla KA, Wolf MT, Daly KA, Reing JE, Badylak SF. Macrophage phenotype as a predictor of constructive remodeling following the implantation of biologically derived surgical mesh materials. Acta Biomater. 2012; 8(3):978-87. [PubMed: 22166681]

14. Brown BN, Valentin JE, Stewart-Akers AM, McCabe GP, Badylak SF. Macrophage phenotype and remodeling outcomes in response to biologic scaffolds with and without a cellular component. Biomaterials. 2009; 30(8):1482-91. [PubMed: 19121538]

15. Fearing BV, Van Dyke ME. In vitro response of macrophage polarization to a keratin biomaterial. Acta Biomater. 2014; 10(7):3136-44. [PubMed: 24726958]

16. Guo R, Merkel AR, Sterling JA, Davidson JM, Guelcher SA. Substrate modulus of 3D-printed scaffolds regulates the regenerative response in subcutaneous implants through the macrophage phenotype and Wnt signaling. Biomaterials. 2015; 73:85-95. [PubMed: 26406449]

17. Madden LR, Mortisen DJ, Sussman EM, Dupras SK, Fugate JA, Cuy JL, Hauch KD, Laflamme MA, Murry CE, Ratner BD. Proangiogenic scaffolds as functional templates for cardiac tissue engineering. Proc Natl Acad Sci U S A. 2010; 107(34):15211-6. [PubMed: 20696917]

18. Sussman EM, Halpin MC, Muster J, Moon RT, Ratner BD. Porous implants modulate healing and induce shifts in local macrophage polarization in the foreign body reaction. Ann Biomed Eng. 2014; 42(7):1508-16. [PubMed: 24248559]

19. Mokarram N, Merchant A, Mukhatyar V, Patel G, Bellamkonda RV. Effect of modulating macrophage phenotype on peripheral nerve repair. Biomaterials. 2012; 33(34):8793-801. [PubMed: 22979988]

20. Reeves AR, Spiller KL, Freytes DO, Vunjak-Novakovic G, Kaplan DL. Controlled release of cytokines using silk-biomaterials for macrophage polarization. Biomaterials. 2015; 73:272-83. [PubMed: 26421484]

21. Spiller KL, Nassiri S, Witherel CE, Anfang RR, Ng J, Nakazawa KR, Yu T, Vunjak-Novakovic G. Sequential delivery of immunomodulatory cytokines to facilitate the M1-to-M2 transition of macrophages and enhance vascularization of bone scaffolds. Biomaterials. 2015; 37:194-207. [PubMed: 25453950]

22. Pajarinen J, Tamaki Y, Antonios JK, Lin TH, Sato T, Yao Z, Takagi M, Konttinen YT, Goodman SB. Modulation of mouse macrophage polarization in vitro using IL-4 delivery by osmotic pumps. J Biomed Mater Res A. 2015; 103(4):1339-45. [PubMed: 25044942]

23. Goodman SB. Wear particles, periprosthetic osteolysis and the immune system. Biomaterials. 2007; 28(34):5044-8. [PubMed: 17645943]

24. Jamsen E, Kouri VP, Olkkonen J, Cor A, Goodman SB, Konttinen YT, Pajarinen J. Characterization of macrophage polarizing cytokines in the aseptic loosening of total hip replacements. Journal of orthopaedic research : official publication of the Orthopaedic Research Society. 2014; 32(9):1241-6. [PubMed: 24897980]

25. Lin TH, Kao S, Sato T, Pajarinen J, Zhang R, Loi F, Goodman SB, Yao Z. Exposure of polyethylene particles induces interferon-gamma expression in a natural killer $\mathrm{T}$ lymphocyte and dendritic cell coculture system in vitro: a preliminary study. J Biomed Mater Res A. 2015; 103(1): 71-5. [PubMed: 24616165] 
26. Pajarinen J, Jamsen E, Konttinen YT, Goodman SB. Innate immune reactions in septic and aseptic osteolysis around hip implants. Journal of long-term effects of medical implants. 2014; 24(4):28396. [PubMed: 25747031]

27. Keeney M, Waters H, Barcay K, Jiang X, Yao Z, Pajarinen J, Egashira K, Goodman SB, Yang F. Mutant MCP-1 protein delivery from layer-by-layer coatings on orthopedic implants to modulate inflammatory response. Biomaterials. 2013; 34(38):10287-95. [PubMed: 24075408]

28. Lin TH, Pajarinen J, Sato T, Loi F, Fan C, Cordova LA, Nabeshima A, Gibon E, Zhang R, Yao Z, Goodman SB. NF-kappaB decoy oligodeoxynucleotide mitigates wear particle-associated bone loss in the murine continuous infusion model. Acta Biomater. 2016

29. Sato T, Pajarinen J, Behn A, Jiang X, Lin TH, Loi F, Yao Z, Egashira K, Yang F, Goodman SB. The Effect of Local IL-4 Delivery or CCL2 Blockade on Implant Fixation and Bone Structural Properties in a Mouse Model of Wear Particle Induced Osteolysis. J Biomed Mater Res A. 2016

30. Brown BN, Mani D, Nolfi AL, Liang R, Abramowitch S, Moalli PA. Characterization of the host inflammatory response following implantation of prolapse mesh in rhesus macaque. Am J Obstet Gynecol. 2015

31. Nolfi AL, Brown BN, Liang R, Palcsey SL, Bonidie MJ, Abramowitch SD, Moalli PA. Host response to synthetic mesh in women with mesh complications. Am J Obstet Gynecol. 2016

32. Orenstein SB, Saberski ER, Kreutzer DL, Novitsky YW. Comparative analysis of histopathologic effects of synthetic meshes based on material, weight, and pore size in mice. J Surg Res. 2012; 176(2):423-9. [PubMed: 22099590]

33. Klinge U, Klosterhalfen B, Birkenhauer V, Junge K, Conze J, Schumpelick V. Impact of polymer pore size on the interface scar formation in a rat model. J Surg Res. 2002; 103(2):208-14. [PubMed: 11922736]

34. Borges J, Mano JF. Molecular interactions driving the layer-by-layer assembly of multilayers. Chem Rev. 2014; 114(18):8883-942. [PubMed: 25138984]

35. Ai H, Jones SA, Lvov YM. Biomedical applications of electrostatic layer-by-layer nano-assembly of polymers, enzymes, and nanoparticles. Cell Biochem Biophys. 2003; 39(1):23-43. [PubMed: 12835527]

36. Macdonald M, Rodriguez NM, Smith R, Hammond PT. Release of a model protein from biodegradable self assembled films for surface delivery applications. J Control Release. 2008; 131(3):228-34. [PubMed: 18721835]

37. Macdonald ML, Rodriguez NM, Shah NJ, Hammond PT. Characterization of tunable FGF-2 releasing polyelectrolyte multilayers. Biomacromolecules. 2010; 11(8):2053-9. [PubMed: 20690713]

38. Shah NJ, Hyder MN, Moskowitz JS, Quadir MA, Morton SW, Seeherman HJ, Padera RF, Spector M, Hammond PT. Surface-mediated bone tissue morphogenesis from tunable nanolayered implant coatings. Sci Transl Med. 2013; 5(191):191ra83.

39. Shah NJ, Hyder MN, Quadir MA, Dorval Courchesne NM, Seeherman HJ, Nevins M, Spector M, Hammond PT. Adaptive growth factor delivery from a polyelectrolyte coating promotes synergistic bone tissue repair and reconstruction. Proc Natl Acad Sci U S A. 2014; 111(35): 12847-52. [PubMed: 25136093]

40. Shah NJ, Macdonald ML, Beben YM, Padera RF, Samuel RE, Hammond PT. Tunable dual growth factor delivery from polyelectrolyte multilayer films. Biomaterials. 2011; 32(26):6183-93. [PubMed: 21645919]

41. Aumsuwan N, Ye SH, Wagner WR, Urban MW. Covalent attachment of multilayers on poly(tetrafluoroethylene) surfaces. Langmuir. 2011; 27(17):11106-10. [PubMed: 21800880]

42. Sicari BM, Dziki JL, Siu BF, Medberry CJ, Dearth CL, Badylak SF. The promotion of a constructive macrophage phenotype by solubilized extracellular matrix. Biomaterials. 2014; 35(30):8605-12. [PubMed: 25043569]

43. Sacerdote P. Opioids and the immune system. Palliat Med. 2006; 20(Suppl 1):s9-15. [PubMed: 16764216]

44. Martucci C, Panerai AE, Sacerdote P. Chronic fentanyl or buprenorphine infusion in the mouse: similar analgesic profile but different effects on immune responses. Pain. 2004; 110(1-2):385-92. [PubMed: 15275790] 
45. Shukla SK, Mishra AK, Arotiba OA, Mamba BB. Chitosan-based nanomaterials: a state-of-theart review. Int J Biol Macromol. 2013; 59:46-58. [PubMed: 23608103]

46. Kong M, Chen XG, Xing K, Park HJ. Antimicrobial properties of chitosan and mode of action: a state of the art review. Int J Food Microbiol. 2010; 144(1):51-63. [PubMed: 20951455]

47. Lee CG, Da Silva CA, Dela Cruz CS, Ahangari F, Ma B, Kang MJ, He CH, Takyar S, Elias JA. Role of chitin and chitinase/chitinase-like proteins in inflammation, tissue remodeling, and injury. Annu Rev Physiol. 2011; 73:479-501. [PubMed: 21054166]

48. den Dekker E, Grefte S, Huijs T, ten Dam GB, Versteeg EM, van den Berk LC, Bladergroen BA, van Kuppevelt TH, Figdor CG, Torensma R. Monocyte cell surface glycosaminoglycans positively modulate IL-4-induced differentiation toward dendritic cells. J Immunol. 2008; 180(6):3680-8. [PubMed: 18322173]

49. Porta C, Riboldi E, Ippolito A, Sica A. Molecular and epigenetic basis of macrophage polarized activation. Seminars in immunology. 2015; 27(4):237-48. [PubMed: 26561250]

50. Tugal D, Liao X, Jain MK. Transcriptional control of macrophage polarization. Arterioscler Thromb Vasc Biol. 2013; 33(6):1135-44. [PubMed: 23640482]

51. Lawrence T, Natoli G. Transcriptional regulation of macrophage polarization: enabling diversity with identity. Nature reviews. Immunology. 2011; 11(11):750-61.

52. Nadkarni SK, Pierce MC, Park BH, de Boer JF, Whittaker P, Bouma BE, Bressner JE, Halpern E, Houser SL, Tearney GJ. Measurement of collagen and smooth muscle cell content in atherosclerotic plaques using polarization-sensitive optical coherence tomography. J Am Coll Cardiol. 2007; 49(13):1474-81. [PubMed: 17397678]

53. Jetten N, Roumans N, Gijbels MJ, Romano A, Post MJ, de Winther MP, van der Hulst RR, Xanthoulea S. Wound administration of M2-polarized macrophages does not improve murine cutaneous healing responses. PLoS One. 2014; 9(7):e102994. [PubMed: 25068282]

54. Wynn TA, Chawla A, Pollard JW. Macrophage biology in development, homeostasis and disease. Nature. 2013; 496(7446):445-55. [PubMed: 23619691]

55. Liu YC, Zou XB, Chai YF, Yao YM. Macrophage polarization in inflammatory diseases. Int J Biol Sci. 2014; 10(5):520-9. [PubMed: 24910531]

56. Udpa N, Iyer SR, Rajoria R, Breyer KE, Valentine H, Singh B, McDonough SP, Brown BN, Bonassar LJ, Gao Y. Effects of chitosan coatings on polypropylene mesh for implantation in a rat abdominal wall model. Tissue Eng Part A. 2013; 19(23-24):2713-23. [PubMed: 23859182]

57. Meyers SR, Grinstaff MW. Biocompatible and bioactive surface modifications for prolonged in vivo efficacy. Chem Rev. 2012; 112(3):1615-32. [PubMed: 22007787]

58. van Bilsen PH, Popa ER, Brouwer LA, Vincent J, Taylor CE, de Leij LF, Hendriks M, van Luyn MJ. Ongoing foreign body reaction to subcutaneous implanted (heparin) modified Dacron in rats. J Biomed Mater Res A. 2004; 68(3):423-7. [PubMed: 14762921]

59. Liu L, Chen G, Chao T, Ratner BD, Sage EH, Jiang S. Reduced foreign body reaction to implanted biomaterials by surface treatment with oriented osteopontin. J Biomater Sci Polym Ed. 2008; 19(6):821-35. [PubMed: 18534099]

60. Khandwekar AP, Patil DP, Hardikar AA, Shouche YS, Doble M. In vivo modulation of foreign body response on polyurethane by surface entrapment technique. J Biomed Mater Res A. 2010; 95(2):413-23. [PubMed: 20648535]

61. McNally AK, Anderson JM. Interleukin-4 induces foreign body giant cells from human monocytes/macrophages. Differential lymphokine regulation of macrophage fusion leads to morphological variants of multinucleated giant cells. Am J Pathol. 1995; 147(5):1487-99. [PubMed: 7485411]

62. Jones JA, McNally AK, Chang DT, Qin LA, Meyerson H, Colton E, Kwon IL, Matsuda T, Anderson JM. Matrix metalloproteinases and their inhibitors in the foreign body reaction on biomaterials. J Biomed Mater Res A. 2008; 84(1):158-66. [PubMed: 17607751]

63. Smith RC, Riollano M, Leung A, Hammond PT. Layer-by-layer platform technology for smallmolecule delivery. Angew Chem Int Ed Engl. 2009; 48(47):8974-7. [PubMed: 19847838]

64. Choi D, Hong J. Layer-by-layer assembly of multilayer films for controlled drug release. Arch Pharm Res. 2014; 37(1):79-87. [PubMed: 24277693] 
65. Luzina IG, Keegan AD, Heller NM, Rook GA, Shea-Donohue T, Atamas SP. Regulation of inflammation by interleukin-4: a review of "alternatives". Journal of leukocyte biology. 2012; 92(4):753-64. [PubMed: 22782966]

66. Luzina IG, Lockatell V, Todd NW, Highsmith K, Keegan AD, Hasday JD, Atamas SP. Alternatively spliced variants of interleukin-4 promote inflammation differentially. Journal of leukocyte biology. 2011; 89(5):763-70. [PubMed: 21285395]

67. Murray PJ, Wynn TA. Obstacles and opportunities for understanding macrophage polarization. Journal of leukocyte biology. 2011; 89(4):557-63. [PubMed: 21248152]

68. Rath M, Muller I, Kropf P, Closs EI, Munder M. Metabolism via Arginase or Nitric Oxide Synthase: Two Competing Arginine Pathways in Macrophages. Frontiers in immunology. 2014; 5:532. [PubMed: 25386178]

69. Wynn TA, Vannella KM. Macrophages in Tissue Repair, Regeneration, and Fibrosis. Immunity. 2016; 44(3):450-62. [PubMed: 26982353]

70. Barron L, Wynn TA. Fibrosis is regulated by Th2 and Th17 responses and by dynamic interactions between fibroblasts and macrophages. Am J Physiol Gastrointest Liver Physiol. 2011; 300(5):G723-8. [PubMed: 21292997]

71. Holt DJ, Chamberlain LM, Grainger DW. Cell-cell signaling in co-cultures of macrophages and fibroblasts. Biomaterials. 2010; 31(36):9382-94. [PubMed: 20932568]

72. Holt DJ, Grainger DW. Multinucleated giant cells from fibroblast cultures. Biomaterials. 2011; 32(16):3977-87. [PubMed: 21397323]

73. Pierce LM, Rao A, Baumann SS, Glassberg JE, Kuehl TJ, Muir TW. Long-term histologic response to synthetic and biologic graft materials implanted in the vagina and abdomen of a rabbit model. Am J Obstet Gynecol. 2009; 200(5):546, e1-8. [PubMed: 19286140] 


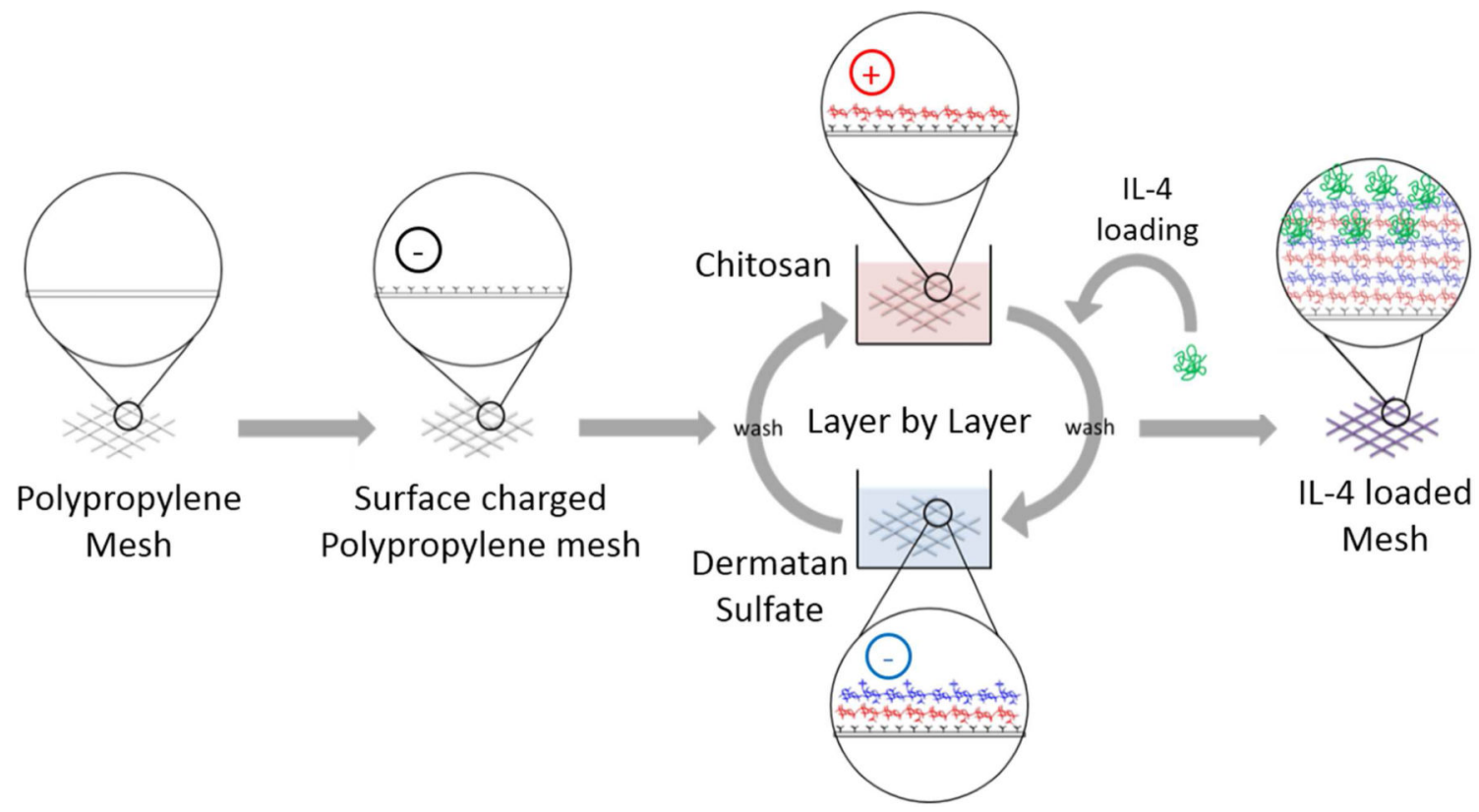

Figure 1.

Schematic of layer by layer coating procedure performed on polypropylene surgical meshes. 
(a)

RFGD
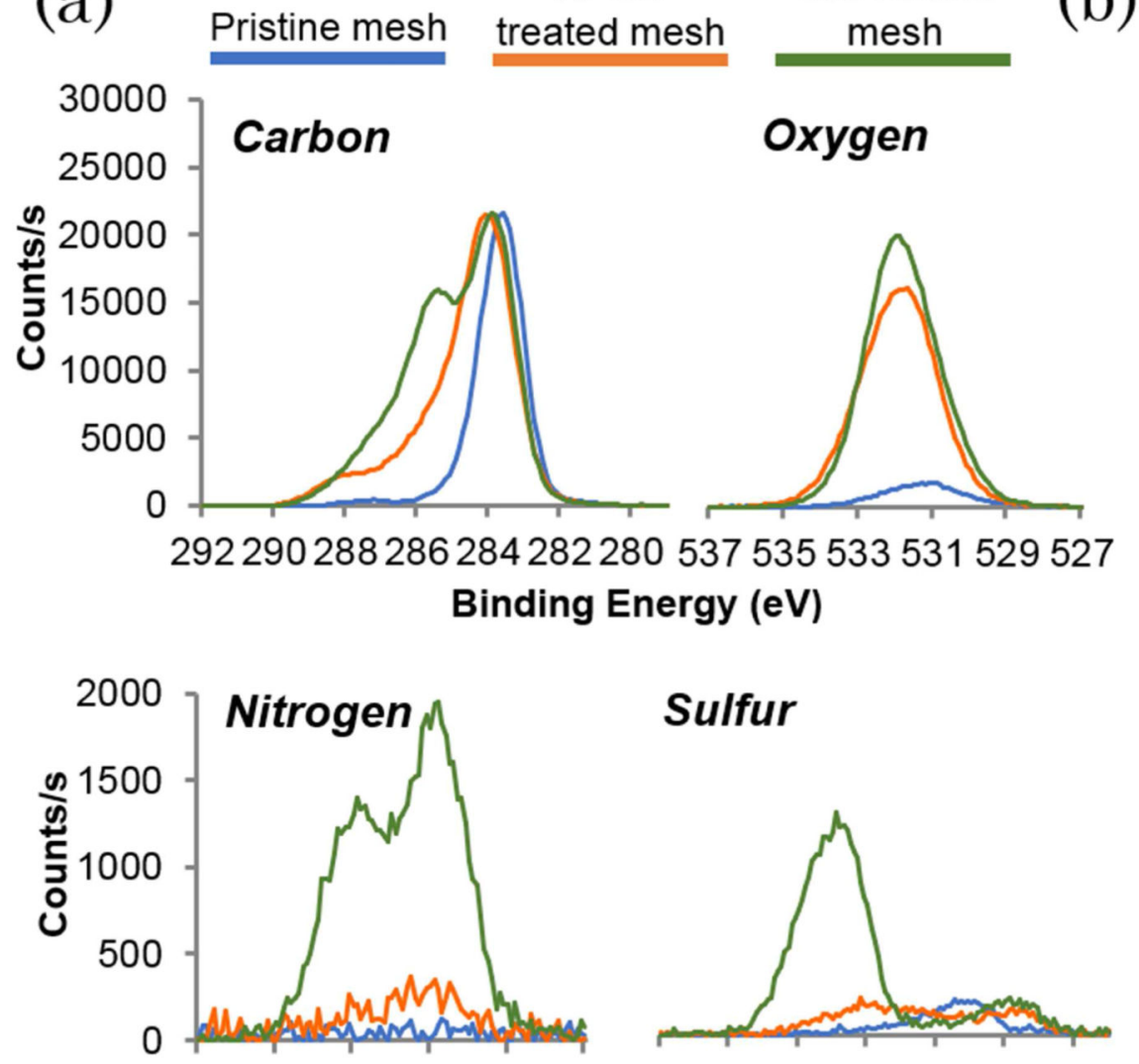

405403401399397395173171169167165163161

Binding Energy (eV)

Sulfur
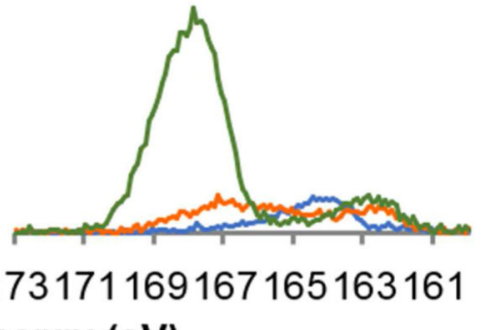

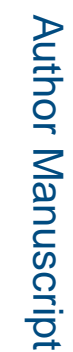

Figure 2.

(a) X-ray photoelectron spectroscopy spectra (XPS) of LbL coated (green), RFGD treated (orange) and pristine (blue) mesh. (b) Images of alcian blue stained $1 \mathrm{~cm}^{2}$ pieces of pristine (i), RFGD treated (ii) and LbL coated meshes (iii). 


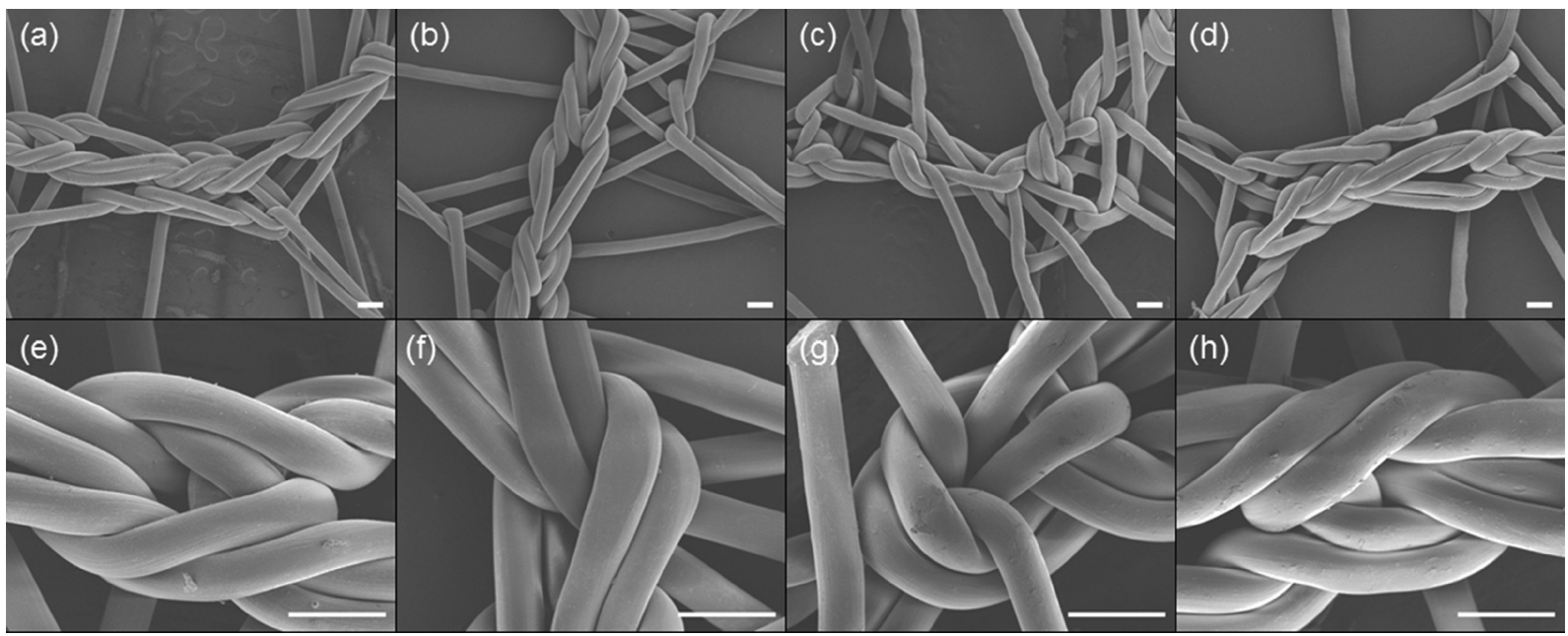

Figure 3.

Scanning electron microscopy images at 40X (a-d) and 150X (e-h) of pristine (a, e), RFGD treated $(b, f)$, LbL coated $(c, g)$ and IL-4 loaded [40B] (d, h) meshes. Scale bars represent $200 \mu \mathrm{m}$. 


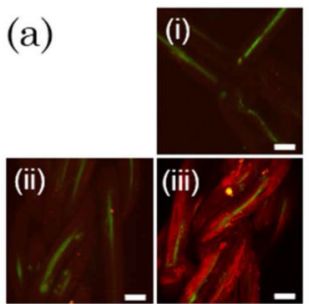

- Coated (no IL-4) mesh

- IL-4 loaded mesh (20 B)

- IL-4 loaded mesh (40B)

- IL-4 loaded mesh (60B) (b)

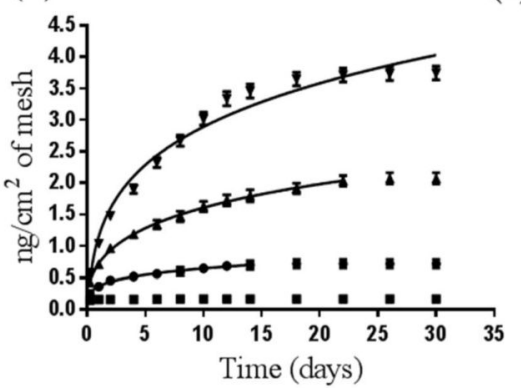

(c)

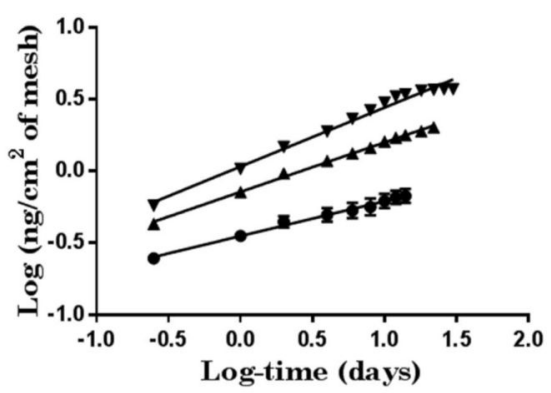

Figure 4.

(a) Confocal microscopy images of IL-4 immunolabeled (red) polypropylene fibers (green) of pristine (i), coated [no IL-4] (ii) and IL-4 loaded [40B] (iii) mesh. Scale bars represent $100 \mu \mathrm{m}$. (b) Cumulative release of IL-4 (nanograms) versus time (days) from $1 \mathrm{~cm}^{2}$ pieces of IL-4 loaded mesh (20, 40 and 60 bilayers). Coated (no IL-4) mesh was used as a control. Power law dependence curves are $\mathrm{y}=0.363 \mathrm{x}^{0.262}\left(\mathrm{r}^{2}=0.995\right), \mathrm{y}=0.718 \mathrm{x}^{0.437}\left(\mathrm{r}^{2}=0.997\right)$ and $y=1.078 x^{0.412}\left(r^{2}=0.983\right)$ for 20,40 and 60 bilayers, respectively. (c) Log - log linear fittings of IL-4 cumulative release versus time. Linear equations are $y=0.242 \mathrm{x}-0.440\left(\mathrm{r}^{2}=\right.$ $0.995), y=0.347 x-0.144\left(r^{2}=0.997\right), y=0.412 x+0.033\left(r^{2}=0.983\right)$ for 20,40 and 60 bilayers, respectively. Points represent the mean \pm SEM. 
(a)

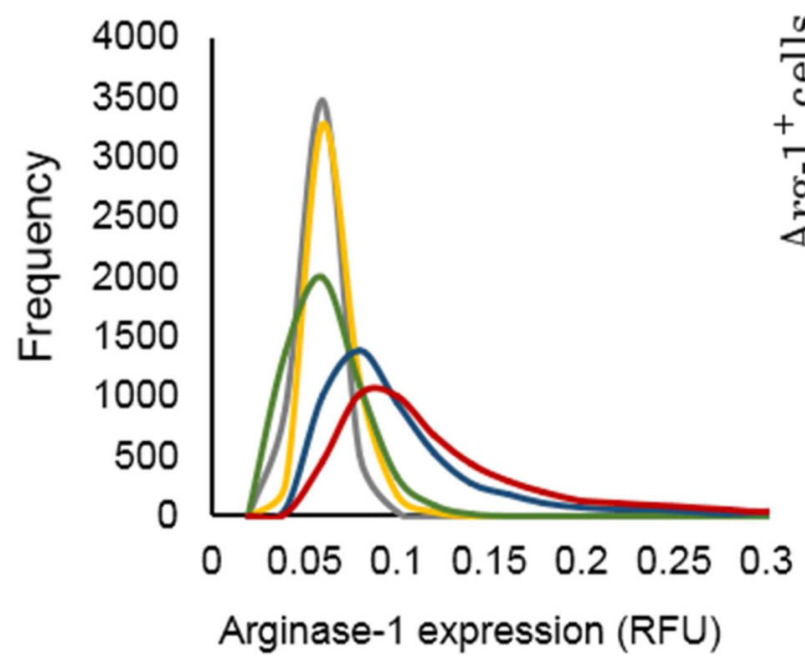

(c)

Pristine mesh

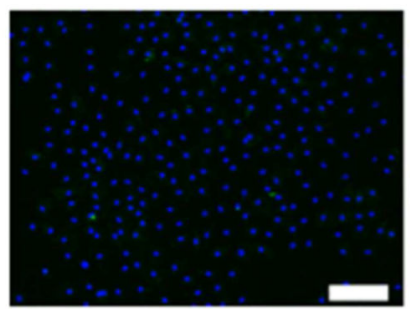

IL-4 loaded mesh (40B)

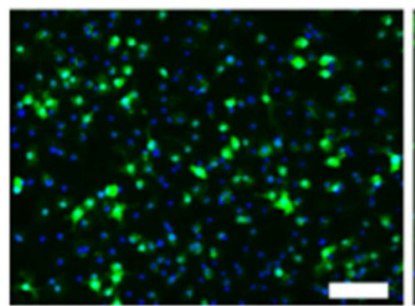

(b)

Coated (no IL-4) mesh

IL -4 (20 ng/mL)

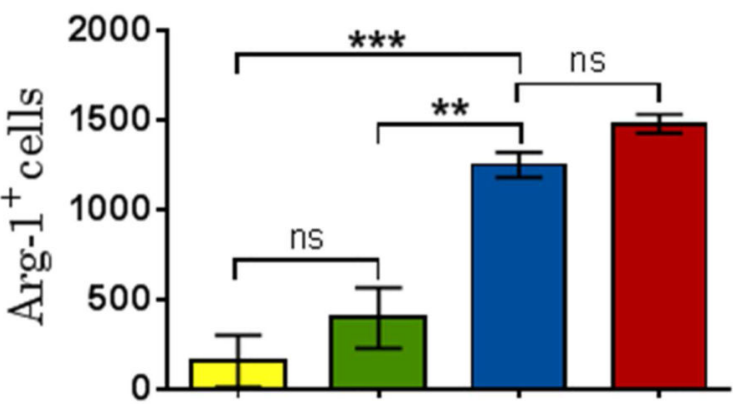

\section{Isotype}

Pristine mesh

Coated (no IL-4) mesh

IL-4 loaded mesh

IL-4 $(20 \mathrm{ng} / \mathrm{mL})$

(d)
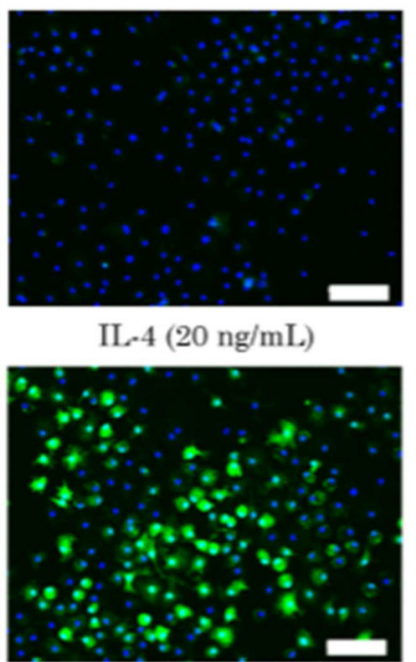

IL-4 Release at $72 \mathrm{hrs}$

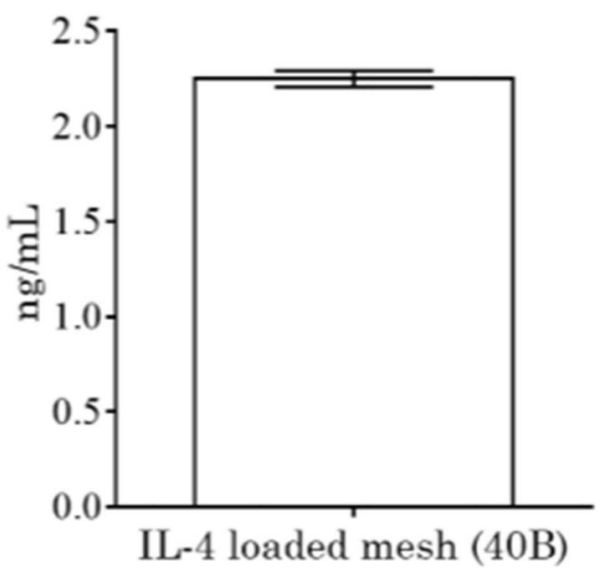

Figure 5.

(a) CellProfiler image analysis from arginase- 1 immunolabeled murine macrophages in an in-vitro culture exposed to $1 \mathrm{~cm}^{2}$ pieces of pristine (yellow), coated [no IL-4] (green) and IL-4 loaded [40B] (blue) mesh. Isotype (gray) and IL-4 [20 ng/mL] (red) were used as negative and positive controls, respectively. (b) Number of arginase-1 positive macrophages determined from the CellProfiler analysis. Bars represent the mean \pm SEM. Statistical significance as $(* *) \mathrm{p}<0.01$ and $(* * *) \mathrm{p}<0.001$, using one-way ANOVA with Tukey's test. (ns) Non-significant. (c) Arginase-1 immunolabelled bone marrow-derived macrophage cultures exposed to $1 \mathrm{~cm}^{2}$ pieces of pristine, coated (no IL-4) and IL-4 loaded (40B) meshes for $72 \mathrm{hrs}$. IL-4 (20 ng/mL) was used as positive control. Scale bars represent $100 \mu \mathrm{m}$. (d) Concentration of IL-4 released by IL-4 loaded meshes ( 40 bilayers) for 72 hours. Bar represents the mean \pm SEM. 


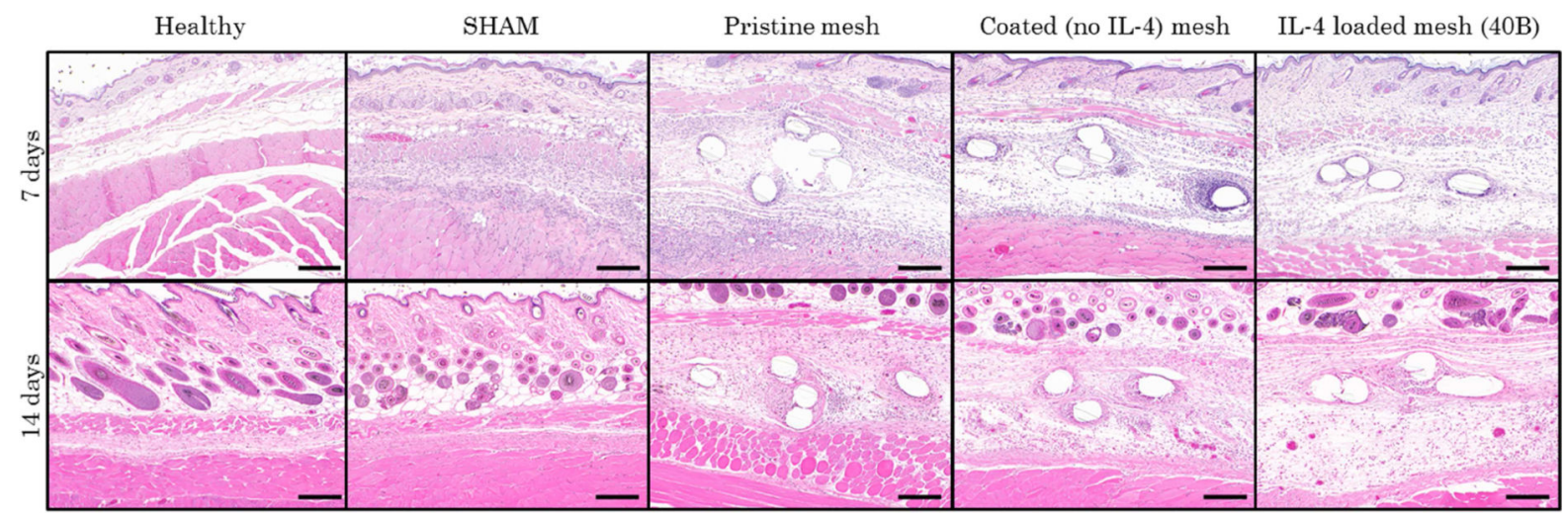

Figure 6.

$\mathrm{H} \& \mathrm{E}$ stained tissue sections at $10 \mathrm{X}$ from mice implanted with a $1 \mathrm{~cm}^{2}$ piece of pristine, coated (no IL-4) and IL-4 loaded (40B) mesh at 7 days (top panel) and 14 days (bottom panel). Healthy and SHAM (no mesh surgery) were used as controls. Scale bars represent $200 \mu \mathrm{m}$. 
(a)

- Arginase-1 O F4/80

O DAPI

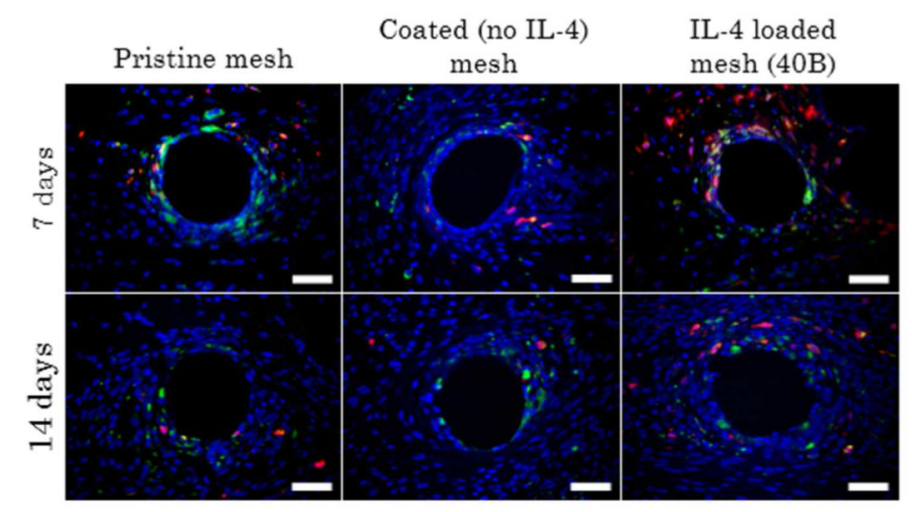

(c)

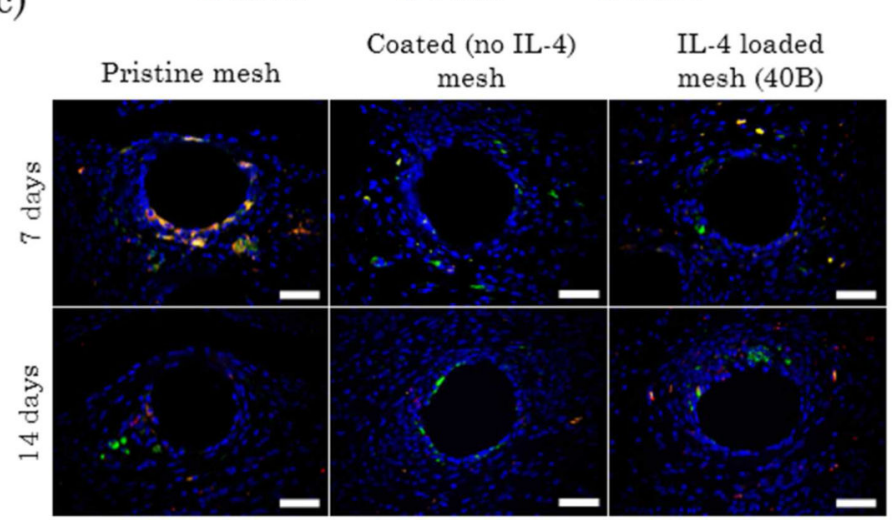

Pristine mesh

Coated (no IL-4) mesh

(b)

A IL-4 loaded mesh (40B)

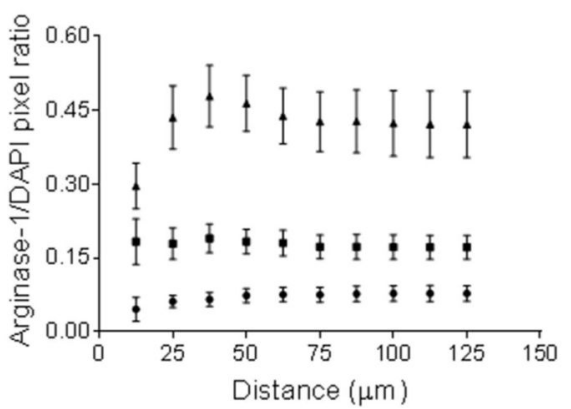

(d)

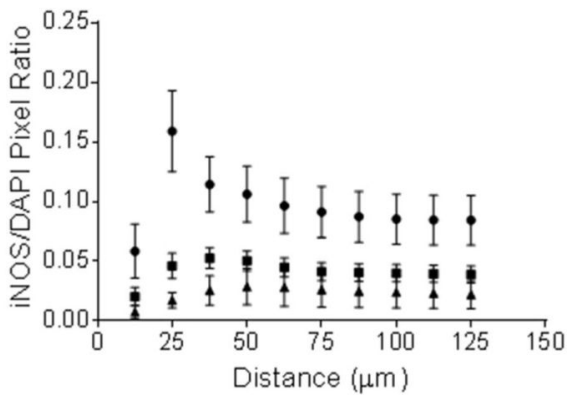

Figure 7.

Fluorescence microscopy images of (a) Arginase-1 (red) and F4/80 (green) coimmunolabeling, and (c) iNOS (red) and F4/80 (green) co-immunolabeling at a single mesh fiber of tissue cross sections of mice implanted with a $1 \mathrm{~cm}^{2}$ piece of pristine, coated (no IL-4) and IL-4 loaded (40B) mesh for 7 days (top panel) and 14 days (bottom panel). DAPI was used to stain cell nuclei. Scale bars represent $50 \mu \mathrm{m}$. (b) Arginase-1/DAPI pixel ratio and (d) iNOS/DAPI pixel ratio versus distance of arginase- 1 and iNOS immunolabeled tissue sections at 7 days, respectively. Points represent the mean $\pm \operatorname{SEM}(N=8)$. 
(a)

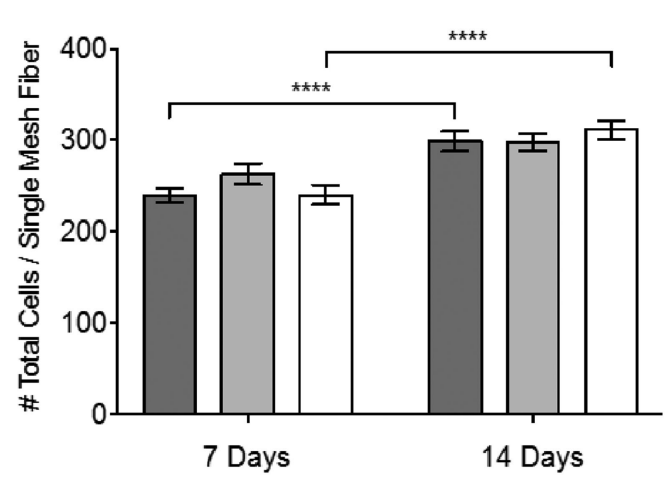

(c)

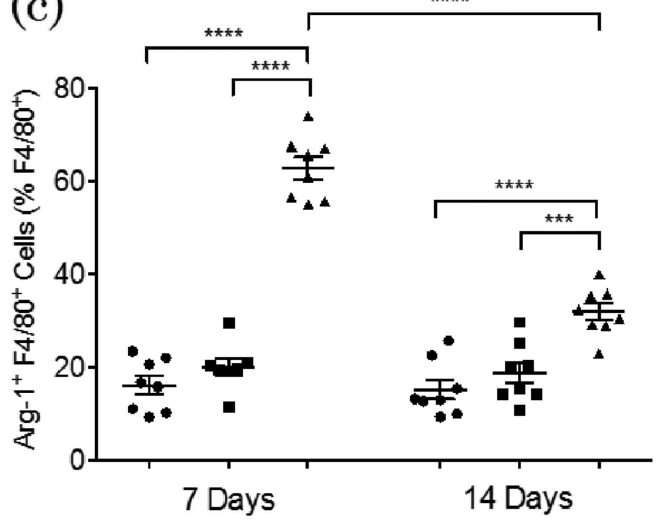

(b)

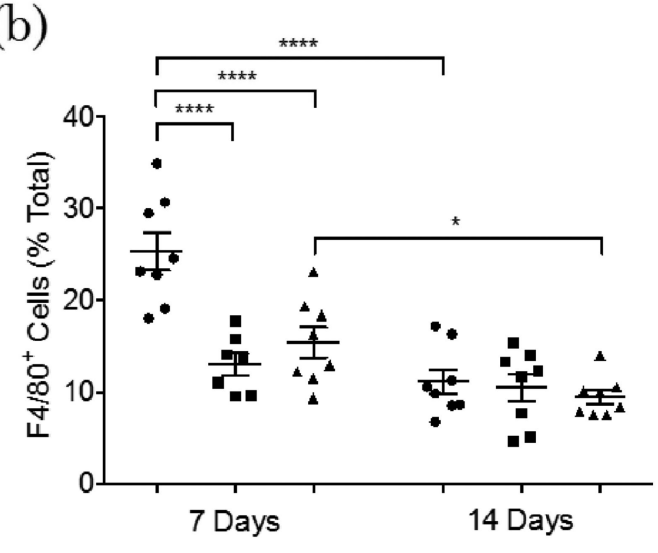

(d)

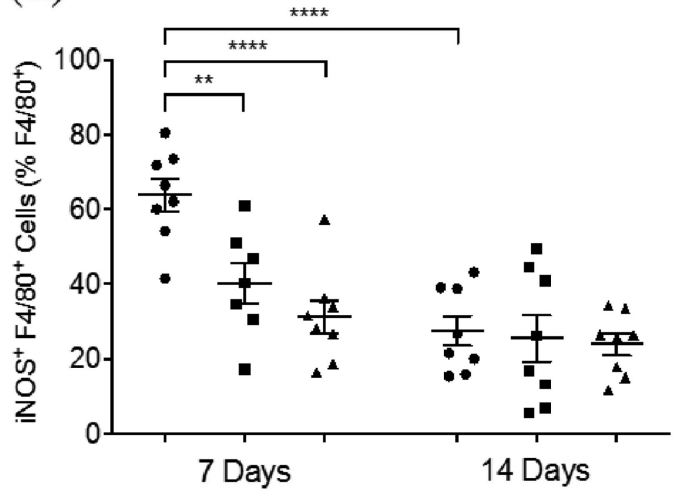

Pristine mesh $\square$ Coated (no IL-4) mesh $\triangle$ IL-4 loaded mesh (40B)

Figure 8.

Image analysis of (a) total cells (DAPI) and (b) $\mathrm{F} 4 / 80^{+}$cells as percentages of total cells (DAPI) surrounding single mesh fibers of tissue cross sections of mice implanted with a 1 $\mathrm{cm}^{2}$ piece of pristine, coated (no IL-4) and IL-4 loaded (40B) mesh for 7 days and 14 days. Image analysis of (c) Arg- $1^{+} \mathrm{F} 4 / 80^{+}$cells and (d) $\mathrm{NOS}^{+} \mathrm{F} 4 / 80^{+}$cells as percentages of total $\mathrm{F} 4 / 80^{+}$cells surrounding single mesh fibers of tissue cross sections of mice implanted with a $1 \mathrm{~cm}^{2}$ piece of pristine, coated (no IL-4) and IL-4 loaded (40B) mesh for 7 days and 14 days. Bars and points represent the mean $\pm \operatorname{SEM}(\mathrm{N}=8)$. Statistical significance as $(*) \mathrm{p}<$ $0.05,(* *) \mathrm{p}<0.01,(* * *) \mathrm{p}<0.001$ and $(* * * *) \mathrm{p}<0.0001$, using two-way ANOVA with Tukey's (groups) and Sidak's (days) tests. All other differences are non-significant. 


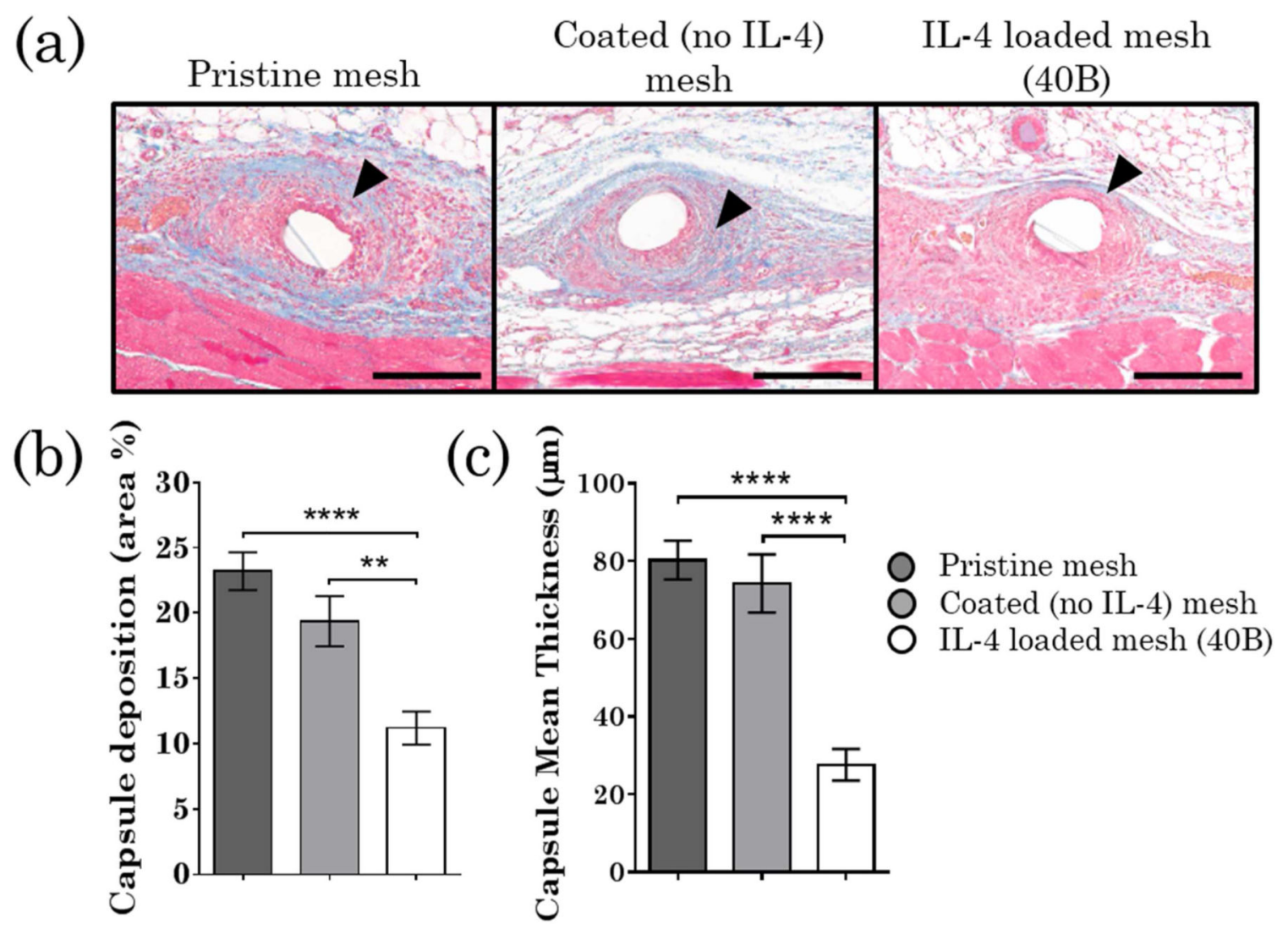

Figure 9.

(a) Masson's Trichrome stained tissue sections of mice implanted with a $1 \mathrm{~cm}^{2}$ piece of pristine, coated (no IL-4) and IL-4 loaded (40B) mesh at 90 days. Arrowheads indicate the capsule surrounding single mesh fibers. Scale bars represent $200 \mu \mathrm{m}$. (b) Image analysis of capsule deposition (area \%) and (c) Mean thickness surrounding mesh fibers (3 images of a single fiber at $20 \mathrm{X}$ per sample, $\mathrm{N}=8$ samples). Bars represent the mean $\pm \mathrm{SEM}$. Statistical significance as $(* *) \mathrm{p}<0.01$ and $(* * * *) \mathrm{p}<0.0001$, using two-way ANOVA with Tukey's test. All other differences are non-significant. 
(a)

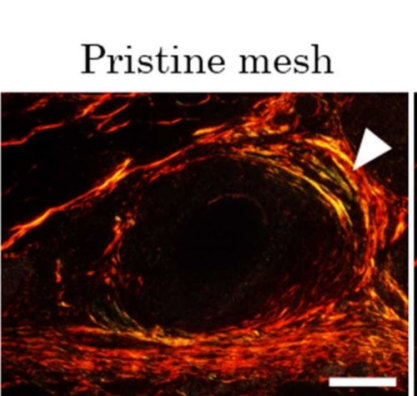

Coated (no IL-4) mesh

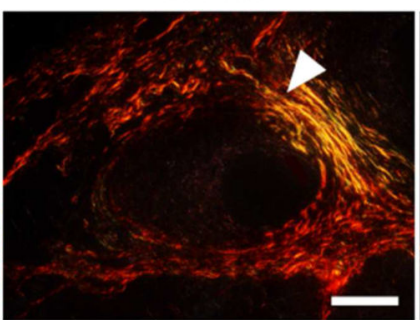

(b)
Thick Collagen Fibers (Orange)
Thin Collagen Fibers (Yellow)
IL-4 loaded mesh

(40B)

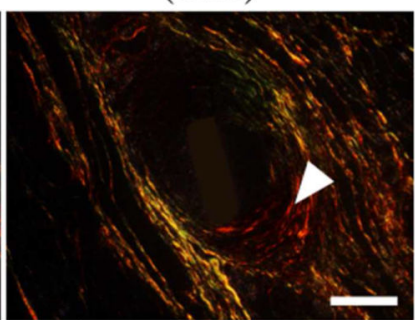

Thinnest Collagen Fibers (Green)

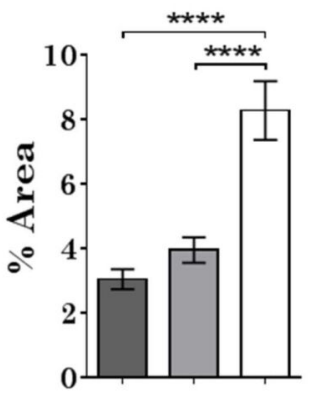

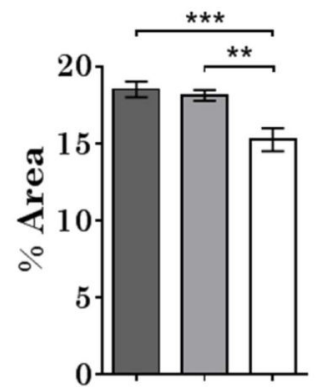

Pristine mesh
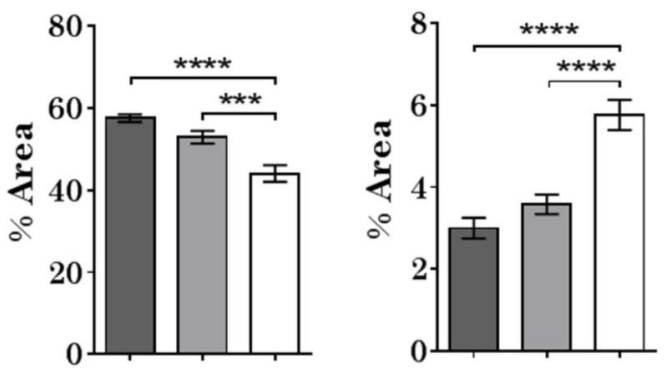

○ Coated (no IL-4) mesh O IL-4 loaded mesh (40B)

Figure 10.

(a) Picro Sirius Red stained tissue sections (20X) of mice implanted with a $1 \mathrm{~cm}^{2}$ piece of pristine, coated (no IL-4) and IL-4 loaded (40B) mesh at 90 days. Arrowheads indicate the capsule surrounding single mesh fibers. Scale bars represent $100 \mu \mathrm{m}$. (b) Image analysis of collagen capsule quality, surrounding mesh fibers (3 images of a single fiber at 20X per sample, $\mathrm{N}=8$ ). Bars represent the mean \pm SEM. Statistical significance as $(* *) \mathrm{p}<0.01$, $(* * *) \mathrm{p}<0.001$ and $(* * * *) \mathrm{p}<0.0001$, using two-way ANOVA with Tukey's test. All other differences are non-significant. 